\title{
Managerial Traits and Capital Structure Decisions
}

\author{
Dirk Hackbarth*
}

\begin{abstract}
This article incorporates well-documented managerial traits into a tradeoff model of capital structure to study their impact on corporate financial policy and firm value. Optimistic and/or overconfident managers choose higher debt levels and issue new debt more often but need not follow a pecking order. The model also surprisingly uncovers that these managerial traits can play a positive role. Biased managers' higher debt levels restrain them from diverting funds, which increases firm value by reducing this manager-shareholder conflict. Although higher debt levels delay investment, mildly biased managers' investment decisions can increase firm value by reducing this bondholder-shareholder conflict.
\end{abstract}

\section{Introduction}

Economists generally focus on models in which agents are rational and have homogeneous expectations. Yet a large and growing body of research in experimental psychology reports that people frequently depart from this traditional paradigm: people tend to be excessively optimistic and overconfident. That is, they predict that favorable future events are more likely than they actually are, and they believe that they have more precise knowledge about future events than they actually have. Top executives are particularly likely to possess such personality

\footnotetext{
*Hackbarth, dhackbar@illinois.edu, College of Business, University of Illinois at UrbanaChampaign, 1206 S 6th St, Champaign, IL 61820. I thank George Akerlof, Itzhak Ben-David, Isabelle Brocas, Armando Gomes, Michael Faulkender, Christopher Hennessy, Ben Hermalin, Yrjö Koskinen, Bart Lambrecht, David Mauer (the referee), Terrance Odean, Enrico Perotti, Matthew Rabin, Jeffrey Wurgler, Xiaoyun Yu, and seminar audiences at Columbia University, Goethe University, Indiana University, New York University, the University of Amsterdam, the 2003 CEPR conference on Economics and Psychology at Humboldt University, and the 2004 EFA Meetings in Maastricht for helpful comments. I am especially indebted to Hayne Leland for his invaluable support while writing my PhD thesis at the University of California at Berkeley, which this article draws on. Some results in this paper were previously circulated under a different title. Financial support by the Haas School of Business and the John M. Olin Foundation is gratefully acknowledged. The usual disclaimer applies.
} 
traits. It is often argued that this has some bearing on corporate decision-making. Consequently, it is important to understand how these managerial traits affect corporate outcomes and hence shareholder welfare. Do managers biased in this way bring potential benefits to the firm?

The corporate finance literature has recently come to consider corporate managers' personality traits. Bertrand and Schoar (2003) document that a significant portion of heterogeneity in firms' financial, investment, and organizational practices is explained by the presence of manager fixed effects. A potential explanation of these findings is the divergence in beliefs of the manager and the market about firm value. ${ }^{1}$ At an intuitive level, managerial traits create heterogeneity among otherwise identical firms. However, managerial traits have so far been discussed only in qualitative terms, and the theoretical literature has largely been silent on the magnitude of their isolated and combined effects on empirically observable corporate outcomes. It would therefore be interesting, for example, to examine whether observed cross-sectional differences in firms' capital structures can be better explained by considering managerial traits.

Building on early structural models such as Fischer, Heinkel, and Zechner (1989), the capital structure literature has established a relation between debt dynamics and various firm and industry characteristics using dynamic contingent claims models. In this paper, I contend that extending traditional tradeoff theory to account for manager characteristics can tighten some important gaps between already known theoretical predictions and as yet unresolved empirical facts. I therefore model explicitly the role of managerial traits as a determinant of corporate outcomes. Their incorporation into a tradeoff model provides answers to such unresolved questions as i) why is there so much cross-sectional variation in capital structure decisions? ii) why do we observe changing capital structure choices for a firm across time, even though the underlying firm and industry characteristics are not changing? and iii) why do certain firms issue only equity rather than a mix of debt and equity?

To address these and related questions, this article develops a tradeoff model of capital structure when the firm's earnings evolve stochastically over time. ${ }^{2}$ Investors are homogeneous and have rational expectations in that they are able to foresee the implications of decision-makers' actions. Managers are also assumed to be rational in all respects, except for how they perceive their firm's

\footnotetext{
${ }^{1}$ Differences of opinion are typically modeled via heterogeneous beliefs and have been included in numerous models that relax the standard homogeneous expectations assumption (e.g., Williams (1977), Harrison and Kreps (1978), and Harris and Raviv (1993)). Differences of opinion may be ascribed to cognitive errors (see Kahneman, Slovic, and Tversky (1982)). Extensive survey evidence compiled by Graham and Harvey (2001) indicates, for example, that most financial managers consistently believe that their company stock is undervalued by the market, deeming heterogeneous beliefs particularly relevant for financial policy.

${ }^{2} \mathrm{An}$ advantage of the contingent claims approach is that it generates quantitative estimates as a function of both the magnitude and the combination of firm and manager characteristics. It also draws on widely accepted models that are frequently argued to offer a consistent and tractable environment for dynamic valuation and hence provide a useful framework to analyze financial policy (e.g., Fischer, Heinkel, and Zechner (1989), Mello and Parsons (1992), Leland (1994), Mauer and Triantis (1994), Parrino and Weisbach (1999), Morellec (2004), Ju, Parrino, Poteshman, and Weisbach (2005), and Mauer and Sarkar (2005)).
} 
growth and risk. That is, optimistic managers overestimate the growth rate of earnings (growth perception bias), while overconfident managers underestimate the riskiness of earnings (risk perception bias). ${ }^{3}$ Thus, the manager's view, which is influenced by personality traits, differs from the market's view, which is not. This difference of opinion persists as the manager, despite knowing the market's view, believes that the market incorrectly values the firm. The market, on the other hand, rationally reacts to the manager's departure from rationality. This enables me to compare and contrast the decisions of biased (i.e., optimistic and overconfident) managers with the decisions of unbiased managers when all decisions are correctly priced by rational investors.

My findings suggest that managerial traits, such as growth and risk perception biases, are important factors for capital structure decisions such as debtequity mix and debt issuance decisions. Managers with growth perception bias overestimate the growth of future earnings generated by their company and hence view external finance as unduly costly. That is, they perceive their companies' risky securities to be undervalued by the market and are therefore reluctant to seek external financing. Because equity prices are generally more sensitive to biases in beliefs, managers with growth perception bias perceive a larger cost to issuing equity than debt. Thus, when they do tap capital markets, they have a standard pecking order preference. In this tradeoff model, the rational market's response to the debt-equity mix being tilted toward debt leads to commensurate discounts on riskier debt and equity, which erodes firm value. On the other hand, managers with risk perception bias surprisingly exhibit the opposite behavior. They underestimate the riskiness of future earnings generated by their company and hence view debt finance as undervalued by the market. The convexity of equity implies, however, that they perceive their firms' equity to be overvalued. Taken together, managers with risk perception bias see a larger benefit in issuing equity than debt, which poses a challenge to the standard paradigm. That is, when managers with risk perception bias raise outside finance, they have a reverse pecking order preference. In this tradeoff model, the rational market's response to the increased number of shares outstanding is to adjust the share price in such a way that the market value of equity remains unchanged. Moreover, when biased managers make debt issuance decisions, their actual choices of debt levels differ from the optimal ones. Managers with growth perception bias believe their firm is more profitable than it actually is and therefore less prone to approach financial distress. Managers with risk perception bias believe their firm is less risky than it actually is and therefore less likely to experience financial distress. Thus, conditional on issuing debt, biased managers choose higher debt levels than unbiased managers. Extending the basic model to debt restructuring demonstrates that biased managers select dynamically higher debt levels and, in expectation, float new debt earlier, which results in shorter debt maturities (refinancing

\footnotetext{
${ }^{3}$ Behavioral economics and finance literature specify several notions of overconfidence. In this article, I follow Kyle and Wang (1997) and Odean (1998) and model overconfidence as miscalibration (i.e., lower risk perception). These authors define overconfidence as an overestimation of signal precision that leads to less dispersed posterior beliefs.
} 
periods). In this tradeoff model, managerial traits lead to costly distortions of debt levels.

Managerial traits enrich tradeoff theory by allowing personal characteristics to have an impact on capital structure decisions. As such, managerial traits theory does not part from traditional capital structure theories. However, it shows that both the magnitude and the combination of managerial biases determine preferences regarding debt vs. equity. Specifically, managerial traits theory is consistent with the standard pecking order prediction for growth perception bias, but perhaps surprisingly, not for risk perception bias. Managerial traits theory therefore complements the understanding of tradeoff theory in interesting ways, which suggests a rethinking of the way capital structure tests are conducted and interpreted.

Capital structure decisions are generally regarded as a tradeoff of a wider range of determinants of not only corporate taxes and bankruptcy costs, but also of conflicts of interests among claimholders. So far, however, we lack any qualitative or quantitative guidance regarding the interactions of agency conflicts and managerial traits. I therefore extend the basic tradeoff model in two ways. First, manager-shareholder conflicts can arise when managers are loath to pay out cash. A common concern with regard to self-interested managers is their tendency to consume private benefits (see Jensen and Meckling (1976)) or to divert discretionary funds (see Hart and Moore (1998)). Static capital structure models therefore emphasize the ex ante perspective that debt, by restricting discretionary funds at the manager's disposal, precommits managers to fewer money-squandering activities (e.g., Grossman and Hart (1982)). A dynamic capital structure model would entail disciplining forces to impose debt issuance initially without the possibility of (partially or even fully) reversing the initial leverage choice later on. An unresolved, albeit important, issue regarding capital structure decisions is that, given that the firm's financing decisions are in the manager's hands, what type of manager is likely to choose these disciplinary debt levels? And, in particular, what type of manager will be most likely to continue an efficiency-enhancing debt policy in a dynamic environment? Second, bondholder-shareholder conflicts arise when firms have risky debt outstanding and maximize equity rather than firm value. The reason for so-called underinvestment is that risky debt captures some investment benefits without bearing any investment costs. Because debtholders anticipate investment behavior, it is impounded into debt values at the issuance date, as an agency cost of debt. Then, underinvestment makes risky debt, ceteris paribus, more costly. The higher initial cost of debt is subsequently the source of inefficient investment behavior when equity value is maximized.

The main result of this paper concerns the interaction of agency problems and managerial traits, when a rational market determines security values based on the capital structure decisions of biased managers. The surprising conclusion I draw is that managerial traits can enhance firm value, for example, when the manager's capital structure decision balances the perceived values of tax benefits, default costs, and self-interest with the need to ensure sufficient efficiency to prevent being replaced. Biased managers believe costs and benefits are optimized by a higher debt coupon. Inefficiently low leverage choices because of the manager's incentive to divert discretionary funds are, therefore, less pronounced 
for managers with growth and risk perception bias. ${ }^{4}$ Thus, biased managers constrain their self-interest more effectively. Managerial traits produce an additional benefit for the firm, but the degree of manager bias matters: Mildly biased managers make capital structure decisions that are more in the interest of shareholders, while extreme managerial biases are detrimental to the firm. ${ }^{5}$

Incorporating irreversible investment into the basic tradeoff model surprisingly uncovers that mildly biased managers can also play a positive role for bondholder-shareholder conflicts. When rational shareholders select default levels, there are two effects. First, biased managers adopt higher debt levels than unbiased managers. All else being equal, higher debt levels aggravate underinvestment, but in fact, the firm value-maximizing investment policy goes handin-hand with higher debt levels. Second, biased managers invest, in expectation, earlier than unbiased managers. This attenuates underinvestment, as long as it is not triggered far too early. That is, when investment is endogenized, managerial traits' impact on firm value is nonmonotone and hence nonstandard in that the agency cost of debt first declines and investor (i.e., initial shareholder) welfare improves. Except when both default and investment are exogenous, mild biases' benefits outweigh their costs, while extreme biases are again detrimental to the firm.

This paper relates to two, so far unrelated, strands of literature. First, it continues the above mentioned line of research, using contingent claims models to analyze financial policy (see footnote 2). To the extent that this literature considers agency problems, conflicts of interest reside between bondholders and shareholders. An exception is Morellec (2004), who develops a dynamic model when self-interested managers make financing decisions to avoid control challenges. Recently, Lambrecht and Myers (2006) studied a contingent claims model in which managers maximize the present value of their future rents, subject to constraints imposed by outside shareholders' property rights to the firm's assets. Second, this paper adds to the small but growing literature on behavioral theories of corporate finance. Roll's (1986) hubris hypothesis of takeovers examines the effect of manager biases on corporate decision-making. Kahnemann and Lovallo (1993) also argue that managers frequently adopt a biased view to achieve the desired outcome. Heterogeneous beliefs among entrepreneurs in the De Meza and Southey (1996) model explain high failure rates, credit rationing, and a preference for debt over equity. Bernardo and Welch (2001) derive an optimal proportion of entrepreneurs that balances information effects against failure rates. Moreover, biased managers are less likely to be arbitraged away in corporations (see Heaton (2002)). Finally, Goel and Thakor (2005) link corporate governance to managerial overconfidence, while Gervais, Heaton, and Odean (2006) analyze the role of overconfidence in capital budgeting decisions. The primary contribution of this

\footnotetext{
${ }^{4}$ For example, Berger, Ofek, and Yermack (1997) report evidence that managerial entrenchment leads to lower leverage.

${ }^{5}$ Recently, Puri and Robinson (2007) provide survey evidence that mild optimism is associated with better decision-making.
} 
paper is to integrate the disparate strands of literature by studying managerial traits in a tradeoff model. ${ }^{6}$

The remainder of the paper is organized as follows. Section II describes the basic model. Section III studies a broad menu of capital structure decisions in the presence of growth and risk perception biases. Section IV extends the basic tradeoff model in several directions, and Section $\mathrm{V}$ provides the conclusions. Most mathematical developments appear in the Appendix.

\section{The Model}

I construct a partial equilibrium model of the firm's capital structure decisions when time is continuous. Consider a firm with activities that require an initial investment $I>0$ at time 0 and subsequently generate earnings before interest and taxes or EBIT, $X(t)>0$. Earnings are observable but nonverifiable, ${ }^{7}$ as in Hart and Moore (1998), and follow a lognormal diffusion process for all $t \in(0, \infty)$ :

$$
d X(t)=\mu X(t) d t+\sigma X(t) d Z(t)
$$

where $\mu$ is the (constant) growth rate of earnings under the risk-neutral measure $\mathcal{Q}, \sigma>0$ denotes the (constant) risk of earnings, $d Z(t)$ is the increment of a standard Wiener process, and the initial value of earnings is $X_{0}>0 .{ }^{8}$ The perfect and rational capital market offers a risk-free return $r>\mu$. A simple tax structure with full loss offset provisions is assumed; that is, there is a constant tax rate $\tau>0$ levied on earnings less debt service whenever applicable. ${ }^{9}$ Goldstein, Ju, and Leland (2001) provide a lucid discussion on the benefits of an EBIT-based formulation for capital structure theory.

Investors are homogeneous and have rational expectations. That is, the market's beliefs are $\mathbf{b}=\{\mu, \sigma\}$, representing growth and risk of earnings given in (1), and, in setting efficient market prices, investors can anticipate the implications of managerial traits. The complex managerial decisions I study in this article are not well suited for learning because they take place infrequently, and feedback is delayed and vague. ${ }^{10}$ I therefore adopt heterogeneous beliefs. Using prime marks to denote biased beliefs, an (over-) optimistic manager exhibits an upward bias

\footnotetext{
${ }^{6}$ For example, recent empirical studies by Ben-David, Graham, and Harvey (2006) and Malmendier, Tate, and Yan (2006) provide strong support for the view that overconfident and optimistic managers bias corporate financial decision-making.

${ }^{7}$ If an earnings-contingent contract could be enforced, the first-best is achieved by writing a complete contract asking the manager to make all corporate decisions corresponding to shareholders' optimal policy.

${ }^{8}$ Alternatively, $\mu$ can be interpreted as the actual growth rate of EBIT under the measure $\mathcal{P}$ when investors are risk-neutral.

${ }^{9}$ I do not explicitly model personal tax rates on debt and equity, and hence $\tau$ may be regarded as the effective tax rate. It would be also straightforward to include a nonlinear tax schedule with switch points from one effective tax rate to another.

${ }^{10}$ Individuals tend to be, for example, more overconfident when difficult tasks require more judgment to evaluate information and when feedback on the quality of judgment is ambiguous in the short run (e.g., Einhorn (1980) and Grifin and Tversky (1992)).
} 
in the perception of growth (growth perception bias): $\mu^{\prime} \in(\mu, r)$, while an overconfident manager has a downward bias in the perception of risk (risk perception bias): $\sigma^{\prime} \in(0, \sigma)$. Finally, a biased manager's beliefs are $\mathbf{b}^{\prime}=\left\{\mu^{\prime}, \sigma^{\prime}\right\}$, which comprise growth and risk perception biases.

Consider a firm with atomistic shareholders who delegate its operations to a manager. To start EBIT generating activities, the firm needs $I$ from external sources at time 0 . That is, suppose investment is exogenous in the basic model, there are no assets in place, and the firm has no cash on hand. I endogenize investment in Section III.B. The manager may issue a single class of debt, paying a promised coupon $C$ to debtholders. Debt is justified by its tax advantage and, for the basic model, remains outstanding forever, unless the firm enters into financial distress (i.e., defaults on its debt obligation). I extend the analysis to debt restructuring in Section III.C. In the event of financial distress, a fraction $\alpha \in] 0,1]$ that represents net bankruptcy costs as a percentage of unlevered firm value $U(X)$ is lost due to direct and indirect costs of financial distress (i.e., default leads to reorganization of assets). The value of the reorganized firm equals $(1-\alpha) U(X)$. Let $X_{d}$ denote the firm's endogenous default threshold, which is selected as a result of optimization (e.g., Leland (1994)).

If it is costly for shareholders to act collectively, it then follows that shareholders cannot directly influence decisions made by management. Therefore, the manager maximizes the perceived value of the firm to existing shareholders. The manager has control over capital structure decisions and hence fills the firm's "financing deficit" with a mix of debt, $D(X, C)$ and equity, $E(X, C)$ :

$$
D(X, C)+\theta E(X, C)=I
$$

where $X \equiv X(t)$ denotes current earnings and $\theta \in[0,1]$ stands for the equity share sold to new shareholders. Note that (2) implies that $(1-\theta) E(X, C)=D(X, C)+$ $E(X, C)-I$ and hence justifies the following objective function for maximizing the perceived value of the firm's marketable claims:

$$
C^{*}(X) \in \arg \max _{C} V(X, C)=D(X, C)+E(X, C),
$$

where $V(X, C)$ denotes levered firm value, which is the sum of risky debt value:

$$
D(X, C)=\mathbb{E}_{t}^{\mathcal{Q}}\left[\int_{t}^{\mathcal{T}_{d}} e^{-r(s-t)} C d s+e^{-r \mathcal{T}_{d}}(1-\alpha) U\left(X\left(\mathcal{T}_{d}\right)\right)\right]
$$

and levered equity value:

$$
E(X, C)=\mathbb{E}_{t}^{\mathcal{Q}}\left[\int_{t}^{\mathcal{T}_{d}} e^{-r(s-t)}(1-\tau)(X(s)-C) d s\right],
$$

and where $\mathbb{E}_{t}^{\mathcal{Q}}[\cdot]$ denotes the conditional expectations operator under $\mathcal{Q}$ at time $t \in$ $[0, \infty)$ and $\mathcal{T}_{d}=\inf \left\{t: X(t) \leq X_{d}\right\}$ is the first time to reach the default threshold. Solving (4) and (5) yields the following closed-form solutions for corporate claim values. (Proofs for all propositions are provided in the Appendix.) 
Proposition 1. Risky debt value equals the sum of discounted coupon flows $C$ and reorganized firm value:

$$
D(X, C)=C / r[1-\mathcal{D}(X)]+(1-\alpha) U\left(X_{d}\right) \mathcal{D}(X) \quad \forall X \geq X_{d},
$$

where the unlevered firm value equals the discounted value of after-tax earnings $(1-\tau) X$ :

$$
U(X)=\mathbb{E}_{t}^{\mathcal{Q}}\left[\int_{t}^{\infty} e^{-r(s-t)}(1-\tau) X(s) d s\right]=(1-\tau) X /(r-\mu),
$$

levered equity equals the discounted value of earnings after interest and tax or dividends $(1-\tau)(X-C)$ :

$$
\begin{aligned}
E(X, C)=(1-\tau)[ & (X /(r-\mu)-C / r) \\
& \left.-\left(X_{d} /(r-\mu)-C / r\right) \mathcal{D}(X)\right] \quad \forall X \geq X_{d},
\end{aligned}
$$

and levered firm value equals the discounted value of dividends plus tax benefits $(1-\tau) X+\tau C$ :

$$
V(X, C)=U(X)+\tau C / r[1-\mathcal{D}(X)]-\alpha U\left(X_{d}\right) \mathcal{D}(X) \quad \forall X \geq X_{d},
$$

where $\mathcal{D}(X)=X^{a} X_{d}^{-a}$ is the stochastic discount factor for default with the characteristic root given by:

$$
a \equiv a(\mu, \sigma)=-\left(\eta+\sqrt{\eta^{2}+2 r \sigma^{2}}\right) \sigma^{-2}<0,
$$

and where $\eta \equiv \mu-\sigma^{2} / 2$.

\section{Capital Structure Decisions}

This section solves the partial equilibrium model of Section II and presents the basic results for managerial traits and capital structure decisions. Specifically, I study default decisions, debt coupon choice and debt-equity mix, and pecking order financing behavior.

The value of all claims satisfies the so-called firm value identity: the perpetual claim value on the firm's unlevered operations, $U(X)$, plus the tax shield value of debt, $T B(X, C)$, minus the bankruptcy costs of debt, $B C(X, C)$, equals levered firm value, $V(X, C)$, according to tradeoff theory:

$$
V(X, C) \equiv U(X)+T B(X, C)-B C(X, C)=D(X, C)+E(X, C),
$$

which, in turn, equals the sum of debt and equity. On the one hand, the tax shield value of debt, $T B(X, C)$, is an increasing and concave function of $X$. If $\tau>0$, there is some lower range in which tax savings suggest higher levels of $C$. With the potential loss of tax shield value benefits in the event of financial distress, $T B(X, C)$ starts to decline with $C$ at a certain point. On the other hand, for $\alpha \in$ ]0, 1] bankruptcy costs, $B C(X, C)$, are increasing and convex in $C$, yet decreasing and convex in $X$. Thus, there exists a unique coupon $C^{*}$ that satisfies (3) so long 
as both taxes and default costs are nontrivial. Solving $\left.(\partial V(X, C) / \partial C)\right|_{C=C^{*}}=0$ yields the firm-value maximizing coupon as a function of beliefs $\mathbf{b}=\{\mu, \sigma\}$ :

$$
C^{*}(X ; \mu, \sigma)=X\left[1-\frac{a(\tau+\alpha(1-\tau))}{\tau}\right]^{1 / a}\left(\frac{a-1}{a}\right)\left(\frac{r}{r-\mu}\right)
$$

where $a=a(\mu, \sigma)<0$ is given in (10). Financial leverage results from the coupon choice in (12) and is defined as the ratio of debt-to-firm value, that is, firm-value maximizing leverage equals:

$$
\ell^{*}(X) \equiv \ell\left(X, C^{*}(X ; \mu, \sigma)\right)=D\left(X, C^{*}(X ; \mu, \sigma)\right) / V\left(X, C^{*}(X ; \mu, \sigma)\right) .
$$

\section{A. Default Decisions}

When default is endogenously determined, there are at least two economic consequences of growth and risk perception biases. First, consider an exogenously given capital structure $C$ that is fixed irrespective of changes in managerial beliefs. The endogenous default policy that maximizes equity value for a given debt level solves $\left.(\partial E(X, C) / \partial X)\right|_{X=X_{d}}=0$, which yields:

$$
X_{d}(X, C ; \mu, \sigma)=C\left(\frac{a}{a-1}\right)\left(\frac{r-\mu}{r}\right),
$$

where $\partial X_{d} / \partial \mu<0$ and $\partial X_{d} / \partial \sigma<0$. As a consequence, optimistic managers $\left(\mu^{\prime}>\mu\right)$ select a lower default level, and overconfident managers $\left(\sigma^{\prime}<\sigma\right)$ select a higher threshold. To put this differently, note that a manager with growth perception bias is more likely to declare default too late (i.e., when earnings are too low). A manager with risk perception bias nonetheless does the opposite. This makes intuitive sense, for in financial distress, both debt and equity exhibit option-like characteristics, and both are driven predominantly by the risk of earnings rather than by their growth rate. Managerial traits hence result also in a divergence from the default policy preferred by rational equity holders.

Second, a crucial feature of the model is that the equilibrium debt level, maximizing firm value, affects the default policy that maximizes equity value. In turn, the equilibrium debt level will not only be affected by the anticipated default threshold, but also by managerial beliefs. Substituting the expression for $C^{*}(X ; \mu, \sigma)$ in (12) into (14) yields a closed-form solution for $X_{d}^{*}$ as a function of beliefs $\mathbf{b}$ :

$$
X_{d}^{*}(X ; \mu, \sigma)=X\left[1-\frac{a(\tau+\alpha(1-\tau))}{\tau}\right]^{1 / a}
$$

which denotes the equilibrium default level (i.e., for an endogenous capital structure). This intuitive and simple expression permits the following result:

Proposition 2. For any perceived firm value-maximizing capital structure decision, optimistic and/or overconfident managers choose a higher default level 
$X_{d}^{*}\left(X ; \mu^{\prime}, \sigma^{\prime}\right)$ and hence enter financial distress earlier. In particular, if $\mu^{\prime} \geq \mu$, then

$$
X_{d}^{*}\left(C ; \mu^{\prime}, \sigma\right) \geq X_{d}^{*}(C ; \mu, \sigma)
$$

for all $\mu \in \mathbb{R}, \mu^{\prime} \in(\mu, r)$, and if $\sigma^{\prime} \leq \sigma$, then

$$
X_{d}^{*}\left(C ; \mu, \sigma^{\prime}\right) \geq X_{d}^{*}(C ; \mu, \sigma)
$$

for all $\sigma \in \mathbb{R}_{+}, \sigma^{\prime} \in(0, \sigma)$.

Several conclusions can be drawn from this result. First, I reverse the previous observation that $X_{d}\left(C ; \mu^{\prime}, \sigma\right)<X_{d}(C ; \mu, \sigma)$ for managers with growth perception bias by incorporating the equilibrium capital structure choice into the analysis. Specifically, an optimistic manager's selected default policy calls for reorganization, in expectation, sooner than the one selected by equityholders. This results from the higher equilibrium capital structure due to growth perception bias. Although equity holders may eventually determine the firm's reorganization point by means of market forces, biased managers' upwardly biased debt coupon choice always raises the equilibrium default threshold that they anticipate. Second, there is a stronger effect of risk perception bias on the manager's equilibrium default policy in (15) relative to (14). In addition to the fact that the value of the option to keep the firm open increases with the risk of earnings in (14), (15) also reflects the effect of risk perception bias on the chosen debt coupon in Proposition 3. Thus, $X_{d}^{*}(\cdot)$ exhibits a steeper slope than $X_{d}(\cdot)$ with respect to earnings risk.

To illustrate these effects, consider a baseline environment in which earnings start at $X_{0}=\$ 20$, the risk-free interest rate is $r=8 \%$, the growth rate of earnings is $\mu=1 \%$, the risk of earnings is $\sigma=25 \%$, corporate taxes are $\tau=15 \%$, and bankruptcy costs are $\alpha=25 \% .{ }^{11}$ For this set of parameter values, Table 1 displays default levels, $X_{d}^{*}$, of an unbiased manager with $\mu=1 \%$ and $\sigma=25 \%$ in the first row of each of the six groups and for a biased manager with growth and/or risk perception biases of $\mu^{\prime} \in\{2 \%, 3 \%\}$ and/or $\sigma^{\prime} \in\{20 \%, 15 \%\}$ in the second and third rows. The left half of the table reports outcomes based on the manager's beliefs, while the right half shows investors' default levels based on the manager's debt levels.

Table 1 contains numerical examples of the effect of managerial traits on default decisions. When biased managers decide upon the corporate financial policies at time 0 , they may believe that they can determine when to default at some future time $\mathcal{T}_{d}>0$, given only their beliefs $\mathbf{b}^{\prime}$. However, rational investors always set fair market prices and hence will pay a non-negative share price up to the default level implied by their beliefs $\mathbf{b}$. Hence, two scenarios arise for the manager's perspective in Table 1. In Panel A, the manager's default threshold solves $\left.(\partial E(X, C) / \partial X)\right|_{X=X_{d}}=0$ using the manager's beliefs $\mathbf{b}^{\prime}$. In contrast, the manager anticipates the market's default threshold, which solves $\left.(\partial E(X, C) / \partial X)\right|_{X=X_{d}}=0$ using the market's beliefs $\mathbf{b}$ (see Panel B). Intermediate cases can be regarded as

\footnotetext{
${ }^{11}$ See Leland (1994) and Ju, Parrino, Poteshman, and Weisbach (2005) on parameter choices for structural models.
} 


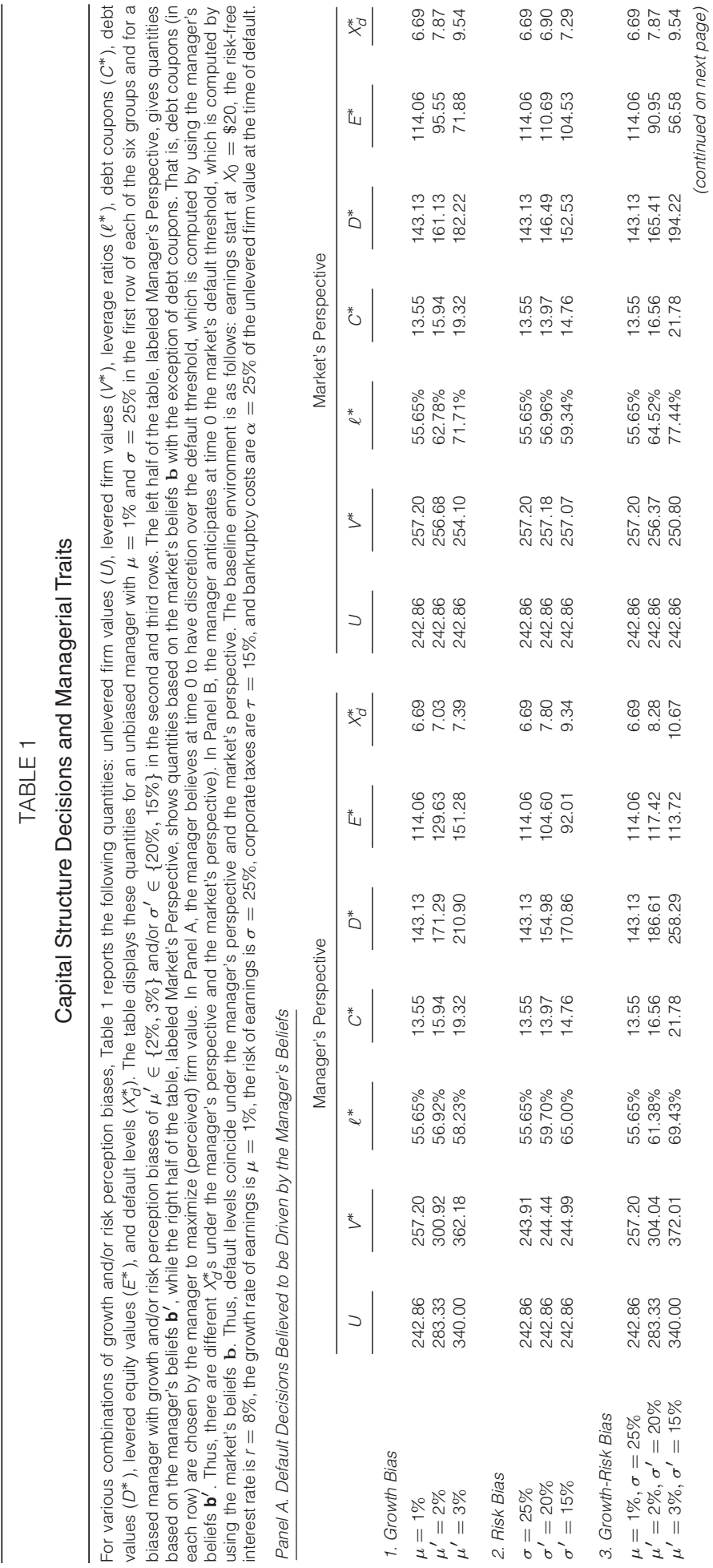


854 Journal of Financial and Quantitative Analysis

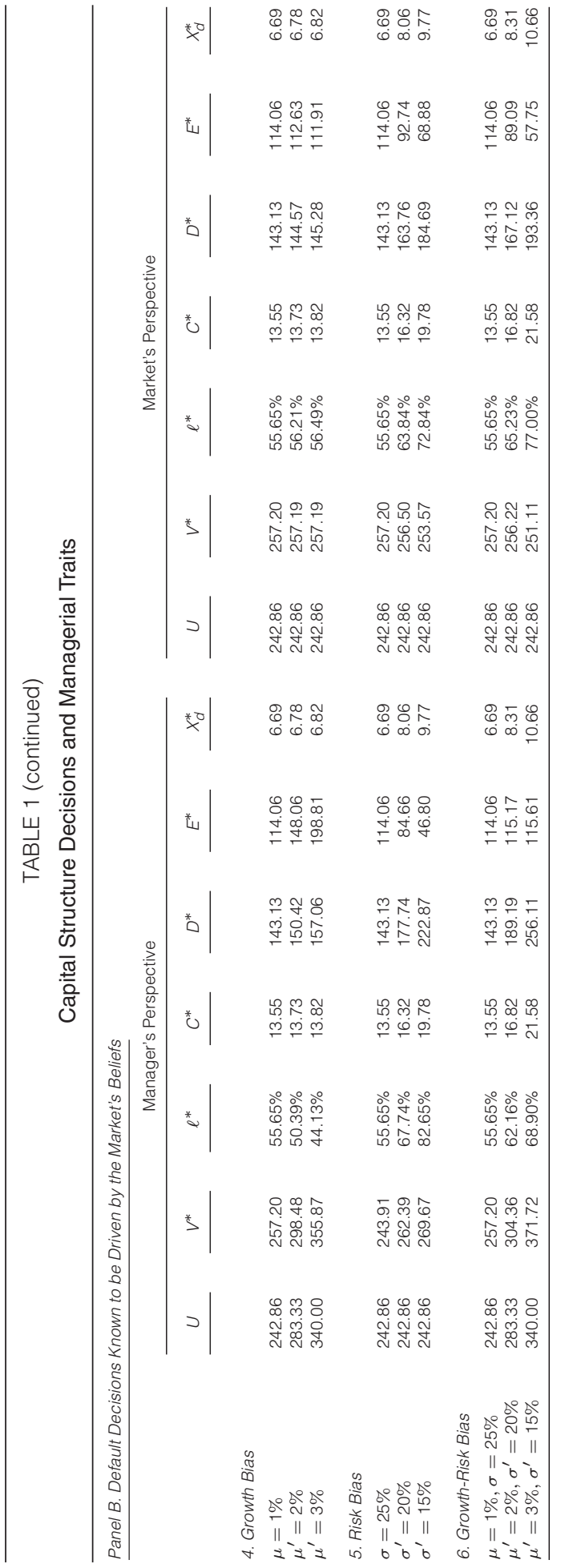


convex combinations of the two scenarios. Within the baseline environment of parameter values, unbiased managers default at $X_{d}^{*}=\$ 6.69$. An optimistic (overconfident) manager, however, wants to default, in expectation, earlier, at $\$ 7.03$ and \$7.39 (\$7.80 and \$9.34). From the market's perspective, growth and risk perception bias increase default levels in several possible ways. First, if the market determines default levels despite the fact that the manager was assumed to do so, then growth (risk) perception bias leads to thresholds of \$7.87 and \$9.54 (\$6.90 and \$7.29). Second, if the manager anticipates at time 0 that the market will select the default policy, then growth (risk) perception bias induces default levels of $\$ 6.78$ and $\$ 6.82$ (\$8.06 and \$9.77). Third, the market's equilibrium default thresholds appear to be more (less) susceptible to growth perception bias than to risk perception bias in Panel A (Panel B). Overall, observe that Table 1 indicates that default decisions can vary dramatically due to managerial traits.

\section{B. Debt Coupon and Debt-Equity Mix Decisions}

\section{Special Case 1: No Bankruptcy Costs and No Corporate Taxes}

In the limit as $\alpha \rightarrow 0$ and $\tau \rightarrow 0$, the Modigliani and Miller (1958) irrelevance of capital structure decisions obtains. It is based on the absence of arbitrage in perfect and rational markets. Interestingly, the presence of biased beliefs, however, makes capital structure decisions relevant even in the absence of taxes and bankruptcy costs. The firm value identity in (11) reduces to:

$$
V(X, C)=U(X)=D(X, C)+E(X, C)
$$

In words, the sum of debt and equity values equals the value of the unlevered firm. Recall that the firm has to raise a given amount of $I$ to initiate its EBIT generating activities. Lemma 1 characterizes the security issuance preferences in this special case of a frictionless world.

Lemma 1. Let $\alpha=0$ and $\tau=0$ hold. Managers with growth perception bias issue debt rather than equity. Managers with risk perception bias, however, are indifferent to the choice of debt or equity.

Proof. Suppose there is a $C$ such that $D(X, C) \geq I$ to ensure feasibility. The first part follows from

$$
D^{\prime}(X, C)-D(X, C)<E^{\prime}(X, 0)-E(X, 0),
$$

which is always satisfied for $\mu^{\prime}>\mu$. This means that for all $\mu^{\prime} \in(\mu, r)$, optimistic managers believe that debt is less underpriced than financing with allequity. Hence the inequality implies a preference for issuing debt. To see this, note that for $C=0$, the firm value identity (18) implies:

$$
U^{\prime}(X)-U(X)=E^{\prime}(X, 0)-E(X, 0) .
$$

Similarly, for $C>0$ the firm value identity (18) implies:

$$
U^{\prime}(X)-U(X)=D^{\prime}(X, C)-D(X, C)+E^{\prime}(X, C)-E(X, C) .
$$


Note that $E^{\prime}(X, C)-E(X, C)>0$ for all $\mu^{\prime}>\mu$ due to the convexity of equity's payoff, and therefore $D^{\prime}(X, C)-D(X, C)<U^{\prime}(X)-U(X)$. The second part follows from the definition of $U(X)$ in (7).

Default does not impose an efficiency loss if $\alpha=0$ and the unlevered firm value depends only on the growth rate. ${ }^{12}$ Therefore, risk perception bias will not affect managers' financial decision-making. Growth perception bias, however, will affect managers' decisions. Although the firm value remains invariant when evaluated at the market's beliefs, optimistic managers' perceived firm value produces a preference for debt finance. Therefore, growth perception bias renders financial policy relevant from a managerial perspective. The behavioral model can explain, for example, why a particular firm's financial policy might slant more toward debt at one time, but favor equity at another point in time, even though the underlying firm fundamentals are not changing. In fact, they have been assumed away in this special case. Consequently, explicit modeling of managerial traits delivers a potentially important determinant of corporate outcomes.

\section{Special Case 2: Bankruptcy Costs without Corporate Taxes}

For $\alpha>0$, default imposes an efficiency loss. The firm value identity (11) changes to:

$$
V(X, C)=U(X)-B C(X, C)=D(X, C)+E(X, C),
$$

and hence growth and risk of earnings affect firm value-maximizing financial structure. Managerial traits now have more subtle implications for corporate financial policies. Without corporate taxes, issuing debt creates no benefits but induces costly financial distress. Equity, in this case, appears to dominate debt.

Lemma 2. Let $\alpha>0$ and $\tau=0$ hold. Managers with growth and/or risk perception bias issue debt rather than equity s.t. $D(X, C) \geq I$ if and only if:

$$
D^{\prime}(X, C)-D(X, C)+B C^{\prime}(X, C)<E^{\prime}(X, 0)-E(X, 0) .
$$

Proof. Follows by inspection of (19).

Lemma 2 states that a preference for debt requires sufficiently larger perceived equity underpricing. That is, a preference for debt requires the perceived underpricing of equity to exceed the perceived underpricing of debt plus perceived bankruptcy costs resulting from debt finance. Depending on the magnitude of default costs and differential beliefs, biased managers may still prefer debt over equity, but not necessarily so. When managerial beliefs are only mildly biased, equity issuance may take place. Capital structure choices can therefore vary at times for a firm, even though the underlying firm and industry characteristics are not changing, simply due to changes in managerial traits.

\footnotetext{
${ }^{12}$ Because I do not explicitly model the firm's operating costs, unlevered firm value is unaffected by risk perception bias. See Mauer and Ott (2000) or Mauer and Sarkar (2005) for an alternative specification of $U(X)$.
} 


\section{Base Case: Bankruptcy Costs and Corporate Taxes}

The base case assumes nontrivial corporate income taxes and nontrivial default costs; that is, $\alpha, \tau>0$. As a result, the firm value-maximizing financial structure in (12) will be determined by the manager's perceived tax shieldbankruptcy cost tradeoff. The manager has the ability to raise firm value by issuing debt that shelters corporate income from tax authorities as long as the risk of entering financial distress is not too imminent. Biased beliefs $\mathbf{b}^{\prime}$ affect the manager's perception of this central tradeoff.

Proposition 3. Managers with growth and/or risk perception bias select higher debt levels. In particular, if $\mu^{\prime} \geq \mu$, then

$$
C^{*}\left(X ; \mu^{\prime}, \sigma\right) \geq C^{*}(X ; \mu, \sigma)
$$

for all $\mu \in \mathbb{R}, \mu^{\prime} \in(\mu, r)$, and if $\sigma^{\prime} \leq \sigma$, then

$$
C^{*}\left(X ; \mu, \sigma^{\prime}\right) \geq C^{*}(X ; \mu, \sigma)
$$

for all $\sigma \in \mathbb{R}_{+}, \sigma^{\prime} \in(0, \sigma)$.

Proposition 3 highlights a few interesting features of managerial traits. First, biased managers are more disposed to debt finance because they believe that the firm is more profitable and/or less risky. Hence, in their view, the firm is less likely to experience financial distress. Second, the model quantifies the isolated and the combined effects of growth and risk perception biases on corporate financial policy.

To understand these results, consider the set of baseline parameter values for which an unbiased manager ( $\mu=1 \%$ and $\sigma=25 \%$ ) selects $55.65 \%$ leverage given a $\$ 13.55$ debt coupon. Consistent with Proposition 3, a larger amount of growth and/or risk perception biases increases debt levels, as seen in Table 1. Turning first to the columns labeled $C^{*}$ in Panel A, an optimistic manager $\left(\mu^{\prime}>\mu\right)$ chooses a debt level of $\$ 15.94$ (\$19.32), which leads to $56.92 \%$ (58.23\%) perceived leverage. Taking as given the manager's biased debt levels, this corresponds to $62.78 \%$ $(71.71 \%)$ actual leverage from the market's perspective. Second, an overconfident manager $\left(\sigma^{\prime}<\sigma\right)$ selects a debt coupon of $\$ 13.97$ (\$14.76), which leads to $59.70 \%(65.00 \%)$ perceived leverage. For the market, this biased debt policy implies only $56.96 \%$ (59.34\%) actual leverage. Thus, debt levels and market leverage have a larger sensitivity to growth perception bias than they have to risk perception bias. But the sensitivity of perceived leverage to growth perception bias is smaller than it is to risk perception bias in Panel A. If the manager anticipates market-determined default, Panel B indicates that debt levels and market leverage are less sensitive to growth perception bias than they are to risk perception bias. Unexpectedly, growth perception bias leads to a decrease in perceived leverage. The reasons for this result are that there is a substantial increase of perceived firm value in the denominator and the upward bias in debt levels is moderated by anticipation of the market's default policy.

In addition to their isolated effects, the model permits an analysis of biases' combined quantitative impact on corporate financial policy and firm value. A manager with growth and risk perception biases believes to lever up the firm to 
$61.38 \%(69.43 \%)$ given a coupon payment of $\$ 16.56(\$ 21.78)$. In the eyes of the market, however, the managerial biases' combined effect yields $64.52 \%(77.44 \%)$ actual leverage. Though there are significant differences between Panels A and B for the isolated effects of growth and risk perception biases, their combined effects lead to a similar variation in debt levels and leverage ratios. Importantly, the table indicates that market leverage ratios can vary dramatically due to managerial traits.

Turning next to the role of growth and risk perception biases for firm value, a biased manager perceives levered firm value to be higher than does an unbiased manager. However, rational investors discount managerial traits' impact on corporate financial policy. In the environment of Panel A in Table 1, growth and risk perception biases lead to distortions in debt and default levels and therefore reduce levered firm value from $\$ 257.20$ by $\$ 0.83$ (\$6.40) to $\$ 256.37$ ( $\$ 250.80$ ), given that the market pays a fair price for any risk-return tradeoff. The negative effect of managerial traits on firm value is comparable in Panel B, when the market controls default levels. In sum, investors commensurately adjust prices to biases in the manager's default and debt policies in that firm value declines by up to $2.5 \%$ in the baseline environment.

\section{Share Repurchases}

The bottom-line of Sections III.B.1 and III.B.2 is that, in contrast to conventional wisdom in the behavioral literature, biased managers can and do perceive equity as either undervalued or overvalued, depending on the degree and type of their biases. For managers with growth perception bias, perceived equity undervaluation provides incentives to repurchase shares in the market. Yet managers have no personal funds, and rational equity holders will not put up cash for such transactions. When share repurchases have to be debt-financed, the incremental tax shield-bankruptcy cost effect must be traded off against the benefits of buying back shares that are perceived to be underpriced. If there are a total of $\vartheta+\zeta$ shares outstanding, from which $\vartheta$ are considered for a repurchase, I can formulate the following result.

Lemma 3. For all $\alpha, \tau, C>0$, optimistic managers who perceive equity to be undervalued by the market issue additional debt with coupon $c>0$ to finance a repurchase of $\vartheta$ shares, as long as:

$$
\begin{aligned}
& {\left[T B^{\prime}(X, C)-B C^{\prime}(X, C)\right]-\left[T B^{\prime}(X, C+c)-B C^{\prime}(X, C+c)\right]} \\
& \quad \leq \frac{\vartheta}{\vartheta+\zeta}\left[E^{\prime}(X, C+c)-E(X, C+c)\right]
\end{aligned}
$$

where the r.h.s. of the inequality has to be less than or equal to $D(X, C+c)-$ $D(X, C)$ to ensure feasibility.

Lemma 3 shows that the perceived cost of additional debt must be offset by the perceived underpricing of equity after the additional debt issuance. Because debt-financed share repurchases increase bankruptcy costs, and because equity value $E(X, C)$ declines with its second argument, there exists an interior solution 
to the (strictly binding) condition in the lemma. The rational market's reaction to the decreased number of shares outstanding and the increased debt coupon is to adjust the share price in such a way that the market value of equity remains unbiased after the share buyback. As a consequence, bias-motivated share buybacks tend to tilt the debt-equity mix more toward debt and to further amplify biased managers' predisposition to debt finance (i.e., $C+c \geq C$ ).

\section{Share Issuance}

On the other hand, for managers with risk perception bias, perceived equity overvaluation provides incentives to issue more shares into the market. The ensuing equity dilution is perceived to be equity value-enhancing. Suppose there are currently $\vartheta$ shares outstanding, and the manager considers $\zeta$ new shares to raise a sum of capital $K$. Then I can make the following observation:

Lemma 4. For all $\alpha, \tau, C>0$, overconfident managers who perceive equity to be overvalued by the market float $\zeta$ new shares to finance a given amount of investment $K>0$, s.t. $\zeta /(\vartheta+\zeta) E(X, C) \leq K$.

Absent other valuation effects, the rational market's reaction to the increased number of shares outstanding is to adjust the share price in such a way that the market value of equity remains unchanged. While equity dilution increases the number of shares outstanding, it does not alter the market value of all shares evaluated at the market's beliefs. Thus, the market value of equity $E(X, C)$ is invariant to the number of shares the manager decides to issue in a frictionless and rational market. ${ }^{13}$ As a consequence, biased managers' share issuance has no corresponding effect on the debt-equity mix being shifted toward equity, nor does it attenuate biased managers' predisposition to debt finance because $C$ does not change.

\section{Pecking Order Financing Behavior}

It has been argued that managers are concerned about the market's underpricing of their firms' securities. Similar to Myers and Majluf (1984), Heaton (2002) shows that optimistic managers follow a pecking order. That is, they have a preference for internal funds if available, debt if external funds are needed, and only as a last resort equity-internal funds are assumed to be exogenously given. Safer securities are taken to be generally less sensitive to biases in beliefs and are thus perceived as less undervalued by the market. On the face of it, biased managers' efforts to minimize unduly high costs of external finance by minimizing the number of risky securities issued gives rise to pecking order financing behavior. To examine this contention, I further develop the results from Proposition 1 based on the manager's debt coupon and default decisions in the preceding sections to express claim values as a function of beliefs $\mathbf{b}=\{\mu, \sigma\}$.

Lemma 5. Given the manager's selected debt level and default level, debt, equity, and firm values are:

\footnotetext{
${ }^{13}$ This is another variant of the Modigliani-Miller Theorem, dealing with the irrelevance of dividend policy.
} 


$$
\begin{aligned}
D^{*}(X)= & U(X)\left\{\left[1-\frac{a(\tau+\alpha(1-\tau))}{\tau}\right]^{1 / a}\right. \\
& \left.\times\left(\frac{1-1 / a}{1-\tau}+\frac{\tau / a}{1-\tau} \frac{1-a(\tau+\alpha(1-\tau))}{\tau-a(\tau+\alpha(1-\tau))}\right)\right\}, \\
E^{*}(X)= & U(X)\left\{\left[1-\frac{a(\tau+\alpha(1-\tau))}{\tau}\right]^{1 / a}\right) \\
& \left.\times\left(\frac{1-a}{a}-\frac{\tau / a}{\tau-a(\tau+\alpha(1-\tau))}\right)+1\right\}, \\
V^{*}(X)= & U(X)\left\{\left[1-\frac{a(\tau+\alpha(1-\tau))}{\tau}\right]^{1 / a}\left(\frac{\tau}{1-\tau}\right)+1\right\} .
\end{aligned}
$$

Lemma 5 reports closed-form expressions for claim values as a function of the manager's beliefs. However, the market uses claim values from Proposition 1 and its beliefs $\mathbf{b}$ together with the manager's biased beliefs $\mathbf{b}^{\prime}$ to anticipate biased decisions. Within the baseline environment, Table 1 also contains numerical examples of the security pricing implications of growth and risk perception biases. The benchmark case of an unbiased manager's decisions and perceived claim values is reported again in the first row of each of the six groups $(\mu=1 \%$ and $\sigma=$ $25 \%)$. The second and third rows consider successively higher degrees of growth and/or risk perception biases. The left half of the table displays the manager's potentially biased perspective, based on Lemma 5, while the right half of the table corresponds to the rational market's valuation of the selected financial policy $C^{*}(X ; \mu, \sigma)$, based on Proposition 1. In Panel B (Panel A), the manager is (not) aware of the fact that default decisions will be in the realm of the rational market.

First, consider the numerical results on debt in the two columns labeled $D^{*}$. In the base case, the price of risky debt amounts to $\$ 143.13$ without managerial biases. In Panel A, a manager with a growth perception bias believes that debt is undervalued by $\$ 10.16$ (\$28.68), while a manager with a risk perception bias views debt as undervalued by $\$ 8.49$ (\$18.33). If the market selects the default level, Panel B documents that the effect of growth (risk) perception bias decreases (increases). Like optimistic managers, overconfident managers therefore perceive debt to be undervalued. Optimism produces a perception of lower default risk due to the higher perceived growth rate of earnings, while overconfidence produces a perception of lower default risk due to the lower risk of earnings. Hence, managers with growth and/or risk perception biases believe that risky debt is worth more than what the market pays for it.

Second, consider the numerical results on equity in the two columns labeled $E^{*}$. In the base case, the price of equity is $\$ 114.06$ without managerial biases. In Panel A, a manager with a growth perception bias regards equity as undervalued by $\$ 34.08$ (\$79.40), while a manager with a risk perception bias thinks that equity 
is overvalued by $\$ 6.09$ (\$12.53). As expected, growth perception bias implies a standard pecking order preference because equity appears more undervalued than debt. Observe that a perceived decline in the risk of earnings lessens the perceived equity value. More interestingly, when the manager only has discretion over the debt but not over the default level, Panel B indicates that the perceived overvaluation of equity increases in absolute and relative terms. The numerical example thus illustrates that, unlike optimistic managers, overconfident managers view equity as overvalued. Surprisingly, risk perception bias produces a reverse pecking order preference, which poses a challenge for the standard paradigm.

Hence, considering only growth perception bias overlooks this potentially important behavioral feature and may obscure the economic effect of common managerial traits on corporate financial decision-making. It also follows that the magnitude and the combination of optimism $\left(\mu^{\prime}>\mu\right)$ and overconfidence $\left(\sigma^{\prime}<\sigma\right)$ are of crucial importance for our understanding of corporate practice (e.g., share buyback vs. SEOs). Specifically, episodes in which biased managers follow a pecking order can persist. But it seems just as likely that they at times perceive debt to be undervalued and equity to be overvalued by the market. In contrast to previous contributions, biased managers therefore need not follow a pecking order. ${ }^{14}$

From an empirical standpoint, a controversy has recently emerged as to whether standard (or modified) pecking order behavior could underlie the observed variations in firms' capital structures (e.g., Frank and Goyal (2003)). Provided that managerial biases affect capital structure in practice, as argued by Ben-David, Graham, and Harvey (2006) and Malmendier, Tate, and Yan (2006), the surprisingly ambiguous effect of growth and risk perception biases on the pecking order may help explain the somewhat inconclusive cross-sectional findings on firms' financing behavior and the standard pecking order prediction.

\section{Extensions}

In this section, I develop three extensions of the basic tradeoff model that capture additional aspects of capital structure decisions and managerial traits. In the first extension, I study a manager-shareholder conflict due to diversion of discretionary funds. The second extension endogenizes investment to analyze a bondholder-shareholder conflict over investment. Finally, I extend the basic framework to incorporate a debt restructuring decision that is a common component of many firms' financing behavior

\section{A. Financing and Diversion Decisions}

A common concern with regard to self-interested managers is that they can, at the expense of shareholders, consume perquisites to their own benefit, giving rise to manager-shareholder conflicts. Jensen (1986) argues that managers may be loath to pay out cash and hence may divert dividends inefficiently given that

\footnotetext{
${ }^{14}$ Similarly, asymmetric information about less risky future earnings results in a reversal of the pecking order pattern.
} 
there are myriad reasons for managers' opportunistic diversion of discretionary resources. The crux of the manager-shareholder conflict is that managers squander diverted funds instead of retaining them efficiently. The manager chooses between paying out all dividends to shareholders and hoarding some dividends internally in a suboptimal fashion. In particular, I focus on the diversion of discretionary funds that, discounted at the appropriate rate, has a negative net present value for equityholders. Consistent with this view, Dittmar and Mahrt-Smith (2007), for example, offer support for a link between discretionary funds and firm performance. Diverted funds in excess of the firm's debt service yield an inefficient return $\delta$ until default, where $\delta<r$, while an efficient project would yield a return of $r$ per unit of account from the perspective of equity. The possibility of diverting funds tends to be limited by disciplinary forces such as the scrutiny of the board of directors and the market of corporate control. Therefore, suppose there is a limit $J>0$ up to which money can be squandered. ${ }^{15}$ Finally, to rule out immediate replacement of the self-interested manager, suppose there is a replacement $\operatorname{cost} L>0$ to lay off the incumbent.

Given that equity holders are risk-neutral, their required rate of return for additional projects is given by the risk-free rate. As a result, the agency cost resulting from diversion of funds satisfies:

$$
A C(X, C ; \delta)=\mathbb{E}_{t}^{\mathcal{Q}}\left[\int_{t}^{\mathcal{T}_{d}} e^{-r(s-t)} d(X(s), C ; r-\delta) d s\right],
$$

where $d(X, C ; \delta)$ denotes the flow from inefficiently diverted funds. Solving (26) yields the following result:

Proposition 4. The agency cost resulting from diversion of funds is given for all $t<\mathcal{T}_{d}$ by:

$$
A C(X, C)=\left\{\begin{array}{ccc}
\psi\left\{\left(\frac{\Pi(a)}{a-z} \frac{X_{l}^{1-z}-X_{h}^{1-z}}{X^{-z}}\right)\left[1-\left(\frac{X}{X_{d}}\right)^{a-z}\right]\right\} & \forall X_{d} \leq X<X_{l}, \\
\psi\left\{\frac{X}{r-\mu}-\frac{C}{r}+\left[\frac{\Pi(a)}{a-z}\left(\frac{X_{h}^{1-z}-X_{l}^{1-z}}{X_{d}^{a-z} X^{-a}}-\frac{X_{h}^{1-z}}{X^{-z}}\right)\right.\right. & \\
\left.\psi\left\{\frac{\Pi(z)}{a-z} \frac{X_{l}^{1-a}}{X^{-a}}\right]\right\} & \\
\frac{J}{r}+\left[\frac { \Pi ( a ) } { a - z } \left(\frac{X_{d}^{z-a}}{\left.X^{-a} X_{h}^{z-1}-\frac{X_{d}^{z-a}}{X^{-a} X_{l}^{z-1}}\right)}\right.\right. & \forall X_{l} \leq X<X_{h}, \\
-\frac{\Pi(z)}{a-z} \frac{\left.\left.X_{h}^{1-a}-X_{l}^{1-a}\right]\right\}}{\left.\left.X^{-a}\right]\right\}} & \forall X_{h} \leq X,
\end{array}\right.
$$

\footnotetext{
${ }^{15} \mathrm{~A}$ less conservative but also realistic assumption would be an unlimited, fractional leakage. Hart and Moore (1998) even consider diversion opportunities in which the manager can "steal the project returns on a one-for-one basis" (p. 2).
} 
where $X_{l}=C, X_{h}=C+J, \psi=r-\delta, \Pi(x)=(x-1) /(r-\mu)-x / r, a$ is given in (10), and $z$ is given by:

$$
z \equiv z(\mu, \sigma)=-\left(\eta-\sqrt{\eta^{2}+2 r \sigma^{2}}\right) \sigma^{-2}>1,
$$

and where $\eta \equiv \mu-\sigma^{2} / 2$ and $X_{d}$ is given by (14).

Proposition 4 provides expressions for the agency cost of the manager's diversion opportunities. Notably, the magnitude of this cost depends on the level of earnings relative to debt coupon and diversion limit. For each region in Proposition 4, the agency cost reflects the diversion flows in the particular region as well as the possibility of moving back and forth between regions. In the low region, where earnings are lower than required debt payments, there is only an option value of moving to the next region. In the medium region, where earnings are higher than required debt payments, the term $\psi[X /(r-\mu)-C / r]$ measures the discounted cost of diversion opportunities. Thus, the function $A C(X, C)$ increases with earnings for some lower range. As diversion opportunities dry up in the high region where earnings exceed the diversion limit plus debt payments, $A C(X, C)$ ultimately becomes independent of earnings and reaches the asymptotic value of $\psi J / r$. As shown in Proposition 4, growth and risk of earnings, which are embedded in the formulas through $a$ and $z$, are again essential in determining claim values in the different regions.

Proposition 4 also shows that rational shareholders properly account for the impact of the manager's self-interest. That is, shareholders would like to enforce returns $r>\delta$ by pricing contingent claims using their discount rate. As is apparent from the Proposition, this return differential represents the source of managershareholder conflict. Hence the levered firm is, in comparison to $V(X, C)$ in (11), given by:

$$
V_{\delta}(X, C)=U(X)+T B(X, C)-B C(X, C)-A C(X, C) .
$$

A new component of the firm value identity is the agency cost associated with diverted funds, indicating that firms without self-interested managers are more valuable. More importantly, the agency cost of diverting funds $A C(X, C)$ declines with $C$. Replacement costs then imply that the manager has the discretion to choose a lower debt level. That is, the self-interested manager's selected debt level solves a boundary condition to avoid replacement rather than a first-order condition to achieve firm value-maximization.

The misalignment of incentives with respect to discretionary funds impacts capital structure decisions. Specifically, the model shows that there are several sources of inefficiency associated with the manager's diversion decision. First, levered firm value declines because of the lower selected debt level and the additional agency cost term in (28). Second, this also produces lower leverage ratios, as observed in practice. Third, due to the resulting change in equity value, the firm's equilibrium default level changes. Finally, since the model encompasses an interaction between diversion opportunities and managerial traits, the following question arises: If one regards manager self-interest as a fact of life, can biased managers make better decisions than their unbiased counterparts? Do managers with growth and risk perception biases bring potential benefits to the firm? Or are 
these managerial traits only detrimental to firm value? Providing qualitative and quantitative answers to these questions is the object of the analysis that follows.

Lemma 6. For a nonzero measure of perceived firm value-maximizing debt levels, managers with growth and/or risk perception biases attenuate the diversion of discretionary funds and hence increase firm value.

Proof. Due to the option-like characteristics of diversion opportunities, their value is always non-negative and their value would be maximized by setting $C=0$. Fix an unbiased manager's self-interested capital structure decision; that is, $C_{m}^{*}(X ; \mu, \sigma)$ solves $V_{\delta}(X, C)=V(X, C)-L$ where $V(X, C)$ and $V_{\delta}(X, C)$ are given in (11) and (28), respectively. By definition, shareholders' firm valuemaximizing capital structure decision satisfies $C_{e}^{*}(X ; \mu, \sigma) \in \arg \max _{C} V(X, C)$, which implies $C_{e}^{*}(X ; \mu, \sigma) \geq C_{m}^{*}(X ; \mu, \sigma)$ and hence $V_{\delta}\left(X, C_{e}^{*}(X ; \mu, \sigma)\right) \geq$ $V_{\delta}\left(X, C_{m}^{*}(X ; \mu, \sigma)\right)$ for all $\delta<r, L \geq 0$, and $X \geq X_{d}$. Note that $V(X, C)$ and $V_{\delta}(X, C)$ are monotonically increasing in $C$ on the interval $\left[C_{m}^{*}(X ; \mu, \sigma), C_{e}^{*}(X\right.$; $\mu, \sigma)]$. It follows from Proposition 3 that biased beliefs imply that $C_{m}^{*}\left(X, \mu^{\prime}, \sigma^{\prime}\right) \geq$ $C_{m}^{*}(X, \mu, \sigma)$ for all $r>\mu^{\prime} \geq \mu$ and $\sigma \geq \sigma^{\prime}>0$. Then, monotonicity implies that $V\left(X, C_{m}^{*}\left(X ; \mu^{\prime}, \sigma^{\prime}\right)\right) \geq V_{\delta}\left(X, C_{m}^{*}\left(X ; \mu^{\prime}, \sigma^{\prime}\right)\right) \geq V_{\delta}\left(X, C_{m}^{*}(X ; \mu, \sigma)\right)$ for all $C_{m}^{*}\left(X ; \mu^{\prime}, \sigma^{\prime}\right)$ on the interval $\left[C_{m}^{*}(X ; \mu, \sigma), C_{e}^{*}(X ; \mu, \sigma)\right]$, which completes the proof.

According to Lemma 6, there exists a nontrivial region to the right of the unbiased manager's debt level in which higher debt levels are efficiency-enhancing because they serve to curb managerial self-interest. In particular, the Lemma shows that self-interested managers select coupon payments as a solution to a boundary value problem, which leads to too low debt levels. Notably, mildly biased managers perceive higher incumbent and replacement firm values. Therefore, constrained maximization with growth and/or risk perception biases implies higher debt levels, which restrict managers from pursuing their own agenda. Put differently, optimistic $\left(\mu^{\prime}>\mu\right)$ and overconfident $\left(\sigma^{\prime}<\sigma\right)$ managers unknowingly constrain their self-interest more than unbiased managers. It is clear now, too, which type of manager commits to pay out funds by adopting higher debt levels and therefore constrains self-interest also in dynamic environments.

To illustrate the arguments above, consider the baseline parameter values from Section III.A and suppose, in addition, that the diversion limit equals $J=$ $\$ 40$, the diversion return is $\delta=4 \%$, and the layoff cost is $L=\$ 8 .{ }^{16}$ Table 2 displays leverage, $\ell$, based on market values of debt, equity, and firm (using the market's beliefs), when the manager determines debt levels $C$, by trading off tax benefits against agency and bankruptcy considerations (using potentially biased beliefs). To compare firm value with managerial self-interest $V_{\delta}$, to firm value without managerial self-interest $V$, I report the difference, Diff., between these two firm values as a measure of the efficiency loss resulting from managerial self-interest. Like Table 1, Table 2 shows outcomes for an unbiased manager ( $\mu=1 \%$ and

\footnotetext{
${ }^{16}$ Economically, this cost captures all frictions associated with a transition from one manager to another and, in particular, from laying off the entrenched incumbent and hiring a replacement manager who does not divert discretionary funds.
} 


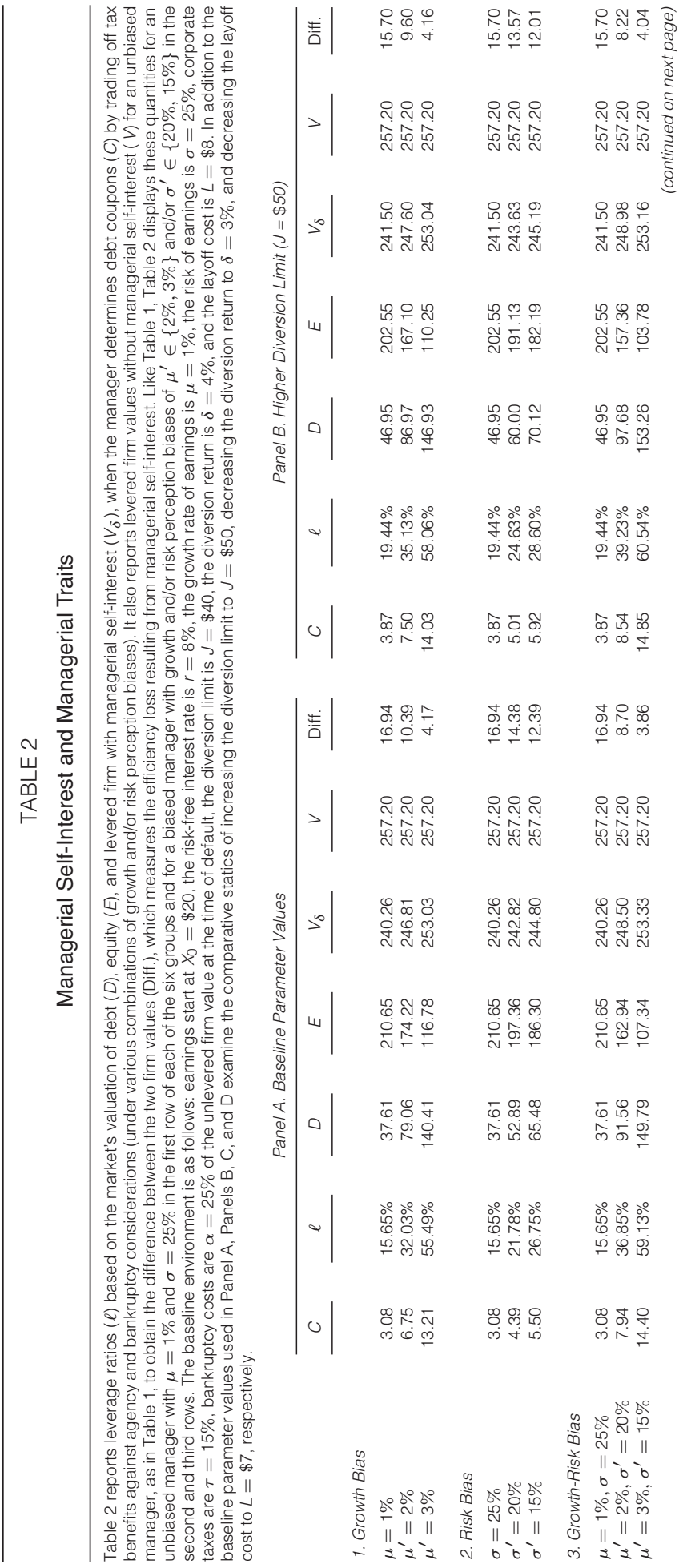




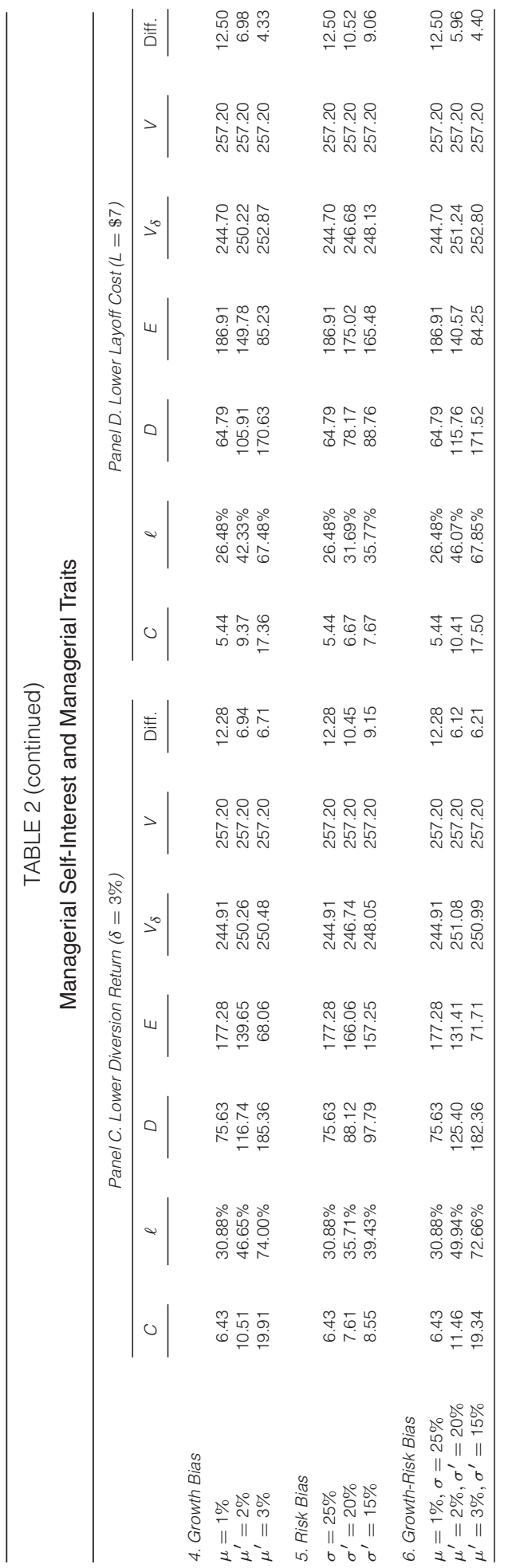


$\sigma=25 \%$ ) in the first row of each of the six groups and for a biased manager with growth and/or risk perception biases of $\mu^{\prime} \in\{2 \%, 3 \%\}$ and/or $\sigma^{\prime} \in\{20 \%, 15 \%\}$ in the second and third rows. Table 2 reveals the following, interesting features of the extended model.

First, the possibility of diverting funds substantially affects capital structure decisions. In the base case, an unbiased manager selects a debt level of $C=\$ 3.08$, which corresponds to $\ell=15.65 \%$ leverage. While a firm without selfinterested management can achieve a maximal value of $V=\$ 257.20$ by issuing a debt coupon of $C^{*}=\$ 13.55$, as seen already in Table 1 , Table 2 indicates that firm value under self-interested management only reaches $V_{\delta}=\$ 240.26$. That is, the efficiency loss caused by the agency cost and the lower tax shield value amounts to $\$ 16.94$. Note that this difference declines dramatically, however, when growth and/or risk perception biases increase. For example, firm value rises to $\$ 253.33$ if $\mu^{\prime}=3 \%$ and $\sigma^{\prime}=15 \%$, and hence the difference in firm values drops to Diff. $=$ $\$ 3.86$ because the biased manager's debt level equals $\$ 14.40$. This coupon payment is higher than the optimal one without managerial self-interest and yet is value-enhancing since the benefit of curbing managerial self-interest outweighs the cost of a suboptimal tax shield-bankruptcy cost tradeoff.

A second feature of the simulations in Table 2 is that variations of the diversion return, the diversion limit, and the layoff cost relative to the base case provide interesting comparative statics. An increase of the diversion limit to $J=\$ 50$ increases the agency cost of diverting funds. To ensure employment, the unbiased manager therefore has to select a higher debt level of $\$ 3.87$ than in the base case. Similarly, a lower diversion return of $\delta=3 \%$ aggravates the agency problem and hence leads the unbiased manager to adopt a slightly more efficient debt policy with a coupon of $\$ 6.43$. Reducing the layoff cost to $L=\$ 7$ has an analogous effect on financial policy. The increased debt payment of $\$ 5.44$ is caused, however, by a decline of the overall frictions associated with a transition from one manager to another rather than by an exacerbated agency conflict. In sum, higher diversion limits, lower diversion returns, and lower layoff costs lead incumbent managers to implement more self-disciplining financial policies.

The third interesting feature of the data reported in Table 2 is that, consistent with economic intuition, variations of the base case parameter values underline the robustness of the result in Lemma 6. While the quantitative effect of managerial traits on firm value varies relative to the base case, the qualitative effect that biased managers can enhance firm value is observable in all simulations. Thus, in the presence of managerial self-interest, mildly biased managers make capital structure decisions that are more in the interest of shareholders than unbiased managers do. In other words, mild biases play a positive role. Extreme biases, however, result in excessive bankruptcy costs relative to increased benefits from self-disciplining debt levels. Consequently, extreme biases have a detrimental effect on firm value.

There are further empirical predictions of the extended tradeoff model. First, to the extent that these effects are capitalized into equity prices, hiring or promoting biased managers should be associated with positive abnormal announcement returns. Second, another implication of these findings is that they might be seen as a rationale for the proliferation of leveraged management buyouts in the 
late 1980s. Indeed, the U.S. experience with leveraged buyouts suggests that firm value may be enhanced by using more leverage.

\section{B. Financing and Investment Decisions}

In this section, I consider interactions between capital structure and investment decisions by introducing assets in place and, in particular, an investment opportunity to expand the firm's earnings at any time by paying a fixed cost. This extension of the behavioral tradeoff model provides insights regarding the role of managerial traits for debt-related investment distortions that lead to bondholdershareholder conflicts.

Debt-related investment distortions arise when firms have risky debt at time 0 and maximize equity rather than firm (i.e., debt plus equity) value at the time of investment. The reason for the resulting underinvestment is that risky debt captures some investment benefits without having to bear any investment costs. Because, on the one hand, rational debtholders anticipate the manager's investment behavior, it is impounded into debt values at time 0 , as an agency cost of debt. Then, underinvestment makes debt, ceteris paribus, more costly. On the other hand, the higher initial cost of debt is subsequently the source of inefficient investment behavior when equity value is maximized at the investment date.

Consider a firm with assets in place that generate earnings according to (1) and hence have a value $U(X)$ given in (7) once the firm's initial "financing deficit" $I_{1}$ is filled. As assumed in Section II, the manager may issue a single class of debt plus equity at time 0 . However, the firm has in addition an irreversible opportunity to scale up earnings by a factor $Q>1$ at a cost of $I_{2}>0$, which is financed with all equity for simplicity. ${ }^{17}$ Thus, the net payoff from exercising the operating option to expand at a given earnings level $X$ equals $(Q-1) X-I_{2}$, which implies that I can write this optimization problem as:

$$
G(X, C)=\sup _{\mathcal{T}_{h}} \mathbb{E}_{t}^{\mathcal{Q}}\left\{e^{-r \mathcal{T}_{h}}\left[(Q-1) X\left(\mathcal{T}_{h}\right)-I_{2}\right]\right\}
$$

where $\mathcal{T}_{h}$ denotes the first passage time to the investment threshold. Let the subscript $l$ denote claim values prior to the event of $X$ reaching $X_{h}$ the first time from below. I then have the following result:

Proposition 5. The manager's selected default and investment thresholds $X_{l}$ and $X_{h}$ solve the equations

$$
\begin{aligned}
X_{l}=(r-\mu)[ & \left(\frac{(Q-1) X_{h}}{r-\mu}-\frac{I_{2}}{1-\tau}-F\left(Q X_{d}, C\right) \mathcal{D}\left(X_{h}\right)\right) \frac{(a-z) X_{l}^{a+z}}{X_{h}^{z} X_{l}^{a}-X_{h}^{a} X_{l}^{z}} \\
& \left.+F\left(X_{l}, C\right) \frac{a X_{h}^{z} X_{l}^{a}-z X_{h}^{a} X_{l}^{z}}{X_{h}^{z} X_{l}^{a}-X_{h}^{a} X_{l}^{z}}\right]
\end{aligned}
$$

\footnotetext{
${ }^{17}$ Allowing $I_{2}$ to be partially financed with additional debt is isomorphic to lowering $I_{2}$, which would accelerate investment. Comingling the gain to equity from issuing debt with the gain to equity from investment does not provide additional insights.
} 
where post-investment default level $X_{d}$ is given by (14) divided by $Q$, for firm or equity value-maximizing investment

$$
\begin{aligned}
& X_{h}=\{ {\left[\frac{(Q-1) X_{h}}{r-\mu}-\left(\frac{\alpha Q X_{d}}{r-\mu}+\frac{\tau}{1-\tau} \frac{C}{r}\right) \mathcal{D}\left(X_{h}\right)\right.} \\
&\left.+\left(\frac{\alpha X_{l}}{r-\mu}+\frac{\tau}{1-\tau} \frac{C}{r}\right) X_{h}^{a} X_{l}^{-a}\right] \\
&\left.\times \frac{(a-z) X_{l}^{a} X_{h}^{z}}{X_{h}^{z} X_{l}^{a}-X_{h}^{a} X_{l}^{z}}-\frac{I_{2}}{1-\tau} \frac{a X_{h}^{a} X_{l}^{z}-z X_{h}^{z} X_{l}^{a}}{X_{h}^{z} X_{l}^{a}-X_{h}^{a} X_{l}^{z}}\right\} \frac{r-\mu}{1-Q}, \\
& X_{h}=\left\{\left(\frac{(Q-1) X_{h}}{r-\mu}-\frac{I_{2}}{1-\tau}-F\left(Q X_{d}, C\right) \mathcal{D}\left(X_{h}\right)\right) \frac{a X_{h}^{a} X_{l}^{z}-z X_{h}^{z} X_{l}^{a}}{X_{h}^{z} X_{l}^{a}-X_{h}^{a} X_{l}^{z}}\right. \\
&\left.+F\left(X_{l}, C\right) \frac{(a-z) X_{h}^{a+z}}{X_{h}^{z} X_{l}^{a}-X_{h}^{a} X_{l}^{z}}-a F\left(Q X_{d}, C\right) \mathcal{D}\left(X_{h}\right)\right\} \frac{r-\mu}{1-Q},
\end{aligned}
$$

where $C$ maximizes $V_{l}\left(X_{0}, C\right)$ and $\mathcal{D}(X)$ as in Proposition 1. Pre-investment debt value is for all $X \in\left(X_{l}, X_{h}\right)$ :

$$
\begin{aligned}
D_{l}(X, C)= & C / r\left[1-\mathcal{L}(X)-\mathcal{D}\left(X_{h}\right) \mathcal{H}(X)\right]+(1-\alpha) U\left(X_{l}\right) \mathcal{L}(X) \\
& +(1-\alpha) U\left(Q X_{d}\right) \mathcal{D}\left(X_{h}\right) \mathcal{H}(X),
\end{aligned}
$$

and post-investment debt value $D(Q X, C)$ is given by (6). Pre-investment equity value satisfies:

$E_{l}(X, C)=(1-\tau)\left[F(X, C)-F\left(X_{l}, C\right) \mathcal{L}(X)-F\left(Q X_{d}, C\right) \mathcal{D}\left(X_{h}\right) \mathcal{H}(X)\right]+G(X, C)$, for all $X \in\left(X_{l}, X_{h}\right)$, where $F(X, C)=X /(r-\mu)-C / r$, the investment option $G(X, C)$ is worth:

$$
G(X, C)=(1-\tau)\left[(Q-1) X_{h} /(r-\mu)-I_{2} /(1-\tau)\right] \mathcal{H}(X),
$$

and post-investment equity value $E(Q X, C)$ is given by (8). Pre-investment firm value satisfies:

$$
\begin{aligned}
V_{l}(X, C)= & U(X)+G(X, C)+\tau C / r\left[1-\mathcal{L}(X)-\mathcal{D}\left(X_{h}\right) \mathcal{H}(X)\right]-\alpha\left[U\left(X_{l}\right) \mathcal{L}(X)\right. \\
& \left.+U\left(Q X_{d}\right) \mathcal{D}\left(X_{h}\right) \mathcal{H}(X)\right]
\end{aligned}
$$

for all $X \in\left(X_{l}, X_{h}\right)$, and post-investment firm value $V(Q X, C)$ is given by (9). In these expressions, the stochastic discount factors $\mathcal{L}(X)$ and $\mathcal{H}(X)$ for default and investment are, respectively, defined by:

$$
\begin{aligned}
\mathcal{L}(X) & =\left(X_{h}^{z} X^{a}-X_{h}^{a} X^{z}\right)\left(X_{h}^{z} X_{l}^{a}-X_{h}^{a} X_{l}^{z}\right)^{-1} \text { and } \\
\mathcal{H}(X) & =\left(X^{z} X_{l}^{a}-X^{a} X_{l}^{z}\right)\left(X_{h}^{z} X_{l}^{a}-X_{h}^{a} X_{l}^{z}\right)^{-1},
\end{aligned}
$$

which denote the present value of $\$ 1$ to be received the first time $X$ reaches $X_{l}$ and $X_{h}$, respectively, conditional on $X$ reaching $X_{l}$ before reaching $X_{h}$ and $X_{h}$ before $X_{l} . a$ and $z$ are given by (10) and (27).

The analytic solutions in Proposition 5 fully characterize corporate decisionmaking when investment is endogenized into the basic model. As indicated by the 
Proposition, the case of equity value-maximizing investment can be contrasted with the hypothetical case in which the manager's investment decision can be contracted upon such that firm value is maximized at the time of investment. ${ }^{18}$ Interchangeably, the latter case is referred to as a first-best $(f b)$ and the former case as a second-best $(s b)$ investment. It is natural to interpret the difference in firm values between these two cases as agency cost of debt:

$$
A C(X, \cdot)=V_{l}\left(X, C^{f b} ; X_{d}^{f b}, X_{l}^{f b}, X_{h}^{f b}\right)-V_{l}\left(X, C^{s b} ; X_{d}^{s b}, X_{l}^{s b}, X_{h}^{s b}\right) .
$$

Because investment behavior interacts with debt and default decisions, it is crucial to distinguish in (33) the debt levels $C^{f b}$ and $C^{s b}$ and the default levels $X_{l}^{f b}$ and $X_{l}^{s b}$ in (30) that are associated with first- and second-best investment levels, $X_{h}^{f b}$ in (31) and $X_{h}^{s b}$ in (32). Thus, a central feature of the extended tradeoff model is that different, i.e., biased, investment behavior goes, in equilibrium, hand-in-hand with correspondingly different debt and default decisions.

To analyze the implications of managerial traits using the results reported in Proposition 5, consider the baseline parameter values from Section III.A and suppose, in addition, that investment benefits are $Q=2.00$ and investment costs are $I_{2}=\$ 200$. For these parameter values, the firm value-maximizing (or first-best) investment decision is to exercise the expansion option when earnings first reach $\$ 32.08$, which leads to a first-best firm value of $\$ 305.57$. By comparison, if the manager chooses the investment policy that maximizes the value of equity at the investment date, the operating option will be exercised when earnings rise the first time to $\$ 34.76$. This implies a second-best firm value of $\$ 300.63$. Thus, the second-best policy exercises the operating option later than the firstbest policy (i.e., $X_{h}^{f b}<X_{h}^{s b}$ ), and underinvestment implies a decline in firm value by $\$ 4.94$, or $1.62 \%$ of first-best firm value. To identify the qualitative and quantitative implications of managerial traits for this bondholder-shareholder conflict over investment, I first examine the effect of growth and risk perception biases on debt, default, and investment. Then I summarize how rational investors incorporate the combination of these effects into firm value.

Observe that the first-best firm value is higher than the the second-best firm value when default and investment are endogenous. As a result, the first-best firm value is maximized at a higher debt level than the second-best firm value or, formally, $C^{f b}>C^{s b}$ in this tradeoff model. In the numerical example of the baseline set of parameters, unbiased managers select a debt level of \$16.03 (\$15.43) under first-best (second-best) investment. Notably, biased managers choose higher debt levels according to Proposition 3. Thus, the fact that growth and/or risk perception biases create a predisposition to higher debt levels causes mildly biased managers' second-best debt levels to approach first-best debt levels of unbiased managers.

Even though the default condition in (30) has the same form for first- and second-best outcomes, the endogeneity of default and investment causes a

\footnotetext{
${ }^{18}$ Equity value-maximizing investment with debt in place corresponds to the objective function proposed by Myers (1977). More recent studies of this case include Mello and Parsons (1992), Parrino and Weisbach (1999), Mauer and Ott (2000), and Childs, Mauer, and Ott (2005), while Mauer and Triantis (1994) focus their analysis on firm value-maximizing investment.
} 
discrepancy between first-best and second-best default, which is due to the divergence of first- and second-best investment in (31) and (32). That is, second-best lies generally below first-best default (i.e., $X_{l}^{s b}<X_{l}^{f b}$ ), as selected debt levels are lower than second-best. Using the baseline environment of parameter values, unbiased managers' first-best (second-best) default level equals \$6.88 (\$6.65). While higher earnings growth or lower earnings risk raise the option value of waiting to default and hence reduces default levels for an exogenous debt policy, the endogeneity of debt and default in this tradeoff model leads to the opposite outcome. Specifically, endogenous debt levels result in an increase of default levels for managers with growth and/or risk perception biases, as already seen in Proposition 2. Hence the perception of higher growth (lower risk) increases default levels of optimistic (overconfident) managers, which enables mildly biased managers' second-best default levels also to approach first-best default levels of unbiased managers. It has been argued earlier that endogenous default is likely driven by capital market forces and hence determined by the market's beliefs. In the analysis that follows, I therefore confine attention to default levels selected by rational shareholders.

As noted above, the interaction of default and investment leads to a discrepancy between first-best and second-best investment levels given by (31) and (32). That is, second-best lies generally above first-best investment (i.e., $X_{h}^{s b}>X_{h}^{f b}$ ) because risky debt captures some investment benefits without having to bear any investment costs. However, increasing growth (decreasing risk) reduces the option value of waiting to invest and hence lowers investment levels. Thus, growth and/or risk perception biases lead to lower perceived investment levels for optimistic and/or overconfident managers, and mildly biased managers' second-best investment levels also move toward first-best investment levels of unbiased managers.

Agency theory asserts that shareholders, as residual claimants, bear the agency cost of debt, which is measured in (33) by the difference in first- and second-best firm values. In a rational market, changes in firm value hence reflect changes in shareholder welfare. To study the combined effect of managerial traits on firm value, Figure 1 charts first-best firm value (dashed line) as a benchmark together with second-best firm value (solid line) using the baseline parameter values. Second-best firm value is computed using rational investors' beliefs $\mathbf{b}$ for valuation, which takes into account, however, the fact that biased managers' beliefs $\mathbf{b}^{\prime}$ can affect debt and investment levels. Notice that the figure contains the earlier example of an unbiased manager's first- and second-best firm values (i.e., $\$ 305.57$ and \$300.63) as a benchmark. While default levels are invariantly determined by shareholders, biased managers can either select the investment level in Graphs A-B or debt and investment levels in Graphs C-D. To compare biased and unbiased managers' decisions, consider changes in optimism $\left(\mu^{\prime}>1 \%\right)$ and overconfidence $\left(\sigma^{\prime}<25 \%\right)$ by moving along the horizontal axes of the graphs. The graphs confirm that the positive effects of growth and risk perception biases on debt and investment carry over to firm valuation. For increasing growth and risk perception biases, all graphs demonstrate that the discrepancy between first- and second-best firm values first declines and subsequently grows again, potentially even beyond the initial difference in firm values. That is, when rational investors impound the separate effects of managerial traits on debt and investment into firm 


\section{FIGURE 1}

Firm Value and Managerial Traits

Graphs A-B depict the effect of growth and risk perception biases on firm value when the manager selects the investment level, while shareholders determine debt and default levels. Graphs C-D chart the effect of growth and risk perception biases on firm value when the manager chooses debt and investment levels, while shareholders determine the default threshold. The dashed lines indicate first-best firm value, and the baseline parameter values of $X_{0}=\$ 20, r=8 \%, \mu=1 \%$, $\sigma=25 \%, \alpha=25 \%, \tau=15 \%, Q=2.00$, and $I_{2}=\$ 200$ are assumed.
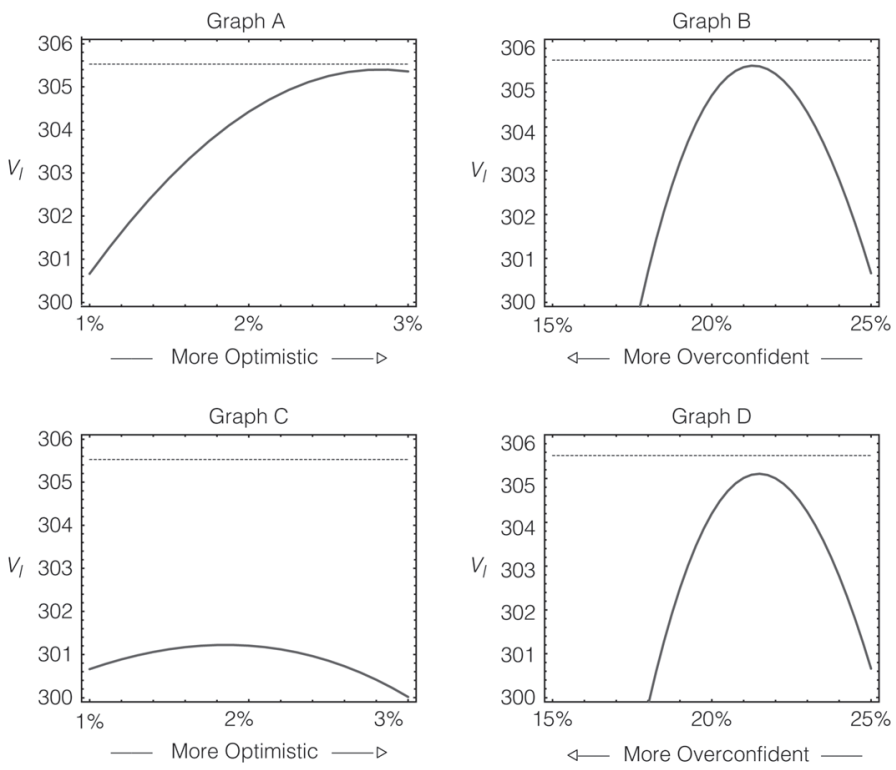

value, mildly biased managers can improve firm value and, in turn, deliver a lower agency cost of debt to shareholders. However, for extreme biases, the second-best firm value of optimistic and/or overconfident managers can drop potentially below that of unbiased managers.

The surprising result is that mild biases can play a positive role. The intuition for this finding is now straightforward. Debt holders' rational expectations permit them to set efficient prices given the firm's risk-return tradeoffs. Interestingly, biased managers who maximize perceived equity value approach unknowingly firstbest policies - more debt, earlier investment, and, if granted, earlier default. As a consequence, debt holders discount the firm's debt less severely, and hence equity holders raise more debt capital under biased management. Though equity value is reduced by biased managers due to increased coupon payments, firm value can increase for mild biases because then the higher proceeds from floating debt can more than offset the decline in equity value. Notice that the reason for the smaller gap between first-best and biased second-best firm values in Graphs A-B relative to $\mathrm{C}-\mathrm{D}$ is precisely that in the former case biased managers cannot distort debt levels. In both scenarios, investor welfare improves. In sum, endogenizing investment into the basic tradeoff model of capital structure therefore indicates that the effect of managerial traits on firm value is nonmonotone and hence nonstandard. 


\section{Debt Restructuring Decisions}

As in Goldstein, Ju, and Leland (2001), I assume for tractability that the manager can only adjust the firm's capital structure upwards. In particular, the firm's restructuring option is modeled as a one-time opportunity to increase debt from a lower level $C_{l}$ to a higher level $C_{h}$, where the firm's initial debt is called at par value (i.e., the initial price of the issue). There are fixed costs $\Gamma>0$ and variable $\operatorname{costs} \gamma D(\cdot)>0$ incurred by the firm at the time of the restructuring. Thus, the net payoff from exercising the option to upward restructure at an arbitrary earnings level $X$ equals:

$$
R(X) \equiv(1-\gamma) D\left(X, C^{*}(X)\right)-P-\Gamma
$$

where $C_{h}$ equals $C^{*}(\cdot)$ in $(12), D(\cdot)$ is defined by (6), and par value $P$ equals initial debt value. In other words, debt restructuring represents an 'irreversible opportunity' to re-optimize the tax shield-bankruptcy cost tradeoff by increasing debt tax shields, which implies that I can write this optimization problem as:

$$
\sup _{\mathcal{T}_{r}} \mathbb{E}_{t}^{\mathcal{Q}}\left\{e^{-r \mathcal{T}_{r}}\left[(1-\gamma) D\left(X_{\mathcal{T}_{r}}, C^{*}\left(X_{\mathcal{T}_{r}}\right)\right)-P-\Gamma\right]\right\}
$$

where $\mathcal{T}_{r}$ denotes the first passage time to the restructuring threshold. Let the subscript $l$ denote claim values prior to the event of $X$ reaching $X_{r}$ the first time from below. I then have the following result:

Proposition 6. The manager's selected default and restructuring thresholds $X_{l}$ and $X_{r}$ solve the equations

$$
\begin{aligned}
X_{l}= & (r-\mu)\left[\left(\frac{C_{l}}{r}+\frac{\tau}{1-\tau} \frac{a C^{*}\left(X_{r}\right)}{r(a-1)}-\frac{P+\Gamma}{1-\tau}\right) \frac{(a-z) X_{l}^{a+z}}{X_{r}^{z} X_{l}^{a}-X_{r}^{a} X_{l}^{z}}\right. \\
& \left.+\left(\frac{X_{l}}{r-\mu}-\frac{C_{l}}{r}\right) \frac{a X_{r}^{z} X_{l}^{a}-z X_{r}^{a} X_{l}^{z}}{X_{r}^{z} X_{l}^{a}-X_{r}^{a} X_{l}^{z}}\right],
\end{aligned}
$$

and

$$
\begin{aligned}
X_{r}= & (r-\mu)\left[\left(\frac{C_{l}}{r}+\frac{\tau}{1-\tau} \frac{a C^{*}\left(X_{r}\right)}{r(a-1)}-\frac{P+\Gamma}{1-\tau}\right) \frac{a X_{r}^{a} X_{l}^{z}-z X_{r}^{z} X_{l}^{a}}{X_{r}^{z} X_{l}^{a}-X_{r}^{a} X_{l}^{z}}\right. \\
& \left.+\left(\frac{X_{l}}{r-\mu}-\frac{C_{l}}{r}\right) \frac{(a-z) X_{r}^{a+z}}{X_{r}^{z} X_{l}^{a}-X_{r}^{a} X_{l}^{z}}\right] / \\
& \left\{\left[\mathcal{D}\left(X_{r}\right)\left[1-\frac{a(\tau+\alpha(1-\tau))}{\tau}\right]^{-1}-\frac{a \tau}{(1-\tau)(a-1)}-1\right]\right. \\
& \left.\times\left[1-\frac{a(\tau+\alpha(1-\tau))}{\tau}\right]^{1 / a} \frac{a-1}{a \mathcal{H}(X)}\right\}
\end{aligned}
$$


where $C_{l}$ maximizes $V_{l}\left(X_{0}, C_{l}\right), C_{h}$ maximizes $V\left(X_{r}, C_{h}\right)$, which yields $C^{*}\left(X_{r}\right)$ in (12), $\mathcal{D}(X)$ is defined in Proposition 1, and par value is $P=D_{l}\left(X_{0}, C_{l}\right)$. Prerestructuring debt value is for all $X \in\left(X_{l}, X_{r}\right)$ :

$$
D_{l}\left(X, C_{l}\right)=C_{l} / r+\left[(1-\alpha) U\left(X_{l}\right)-C_{l} / r\right] \mathcal{L}(X)+\left[P-C_{l} / r\right] \mathcal{H}(X)
$$

and post-restructuring debt value $D\left(X, C^{*}\left(X_{r}\right)\right)$ is given by (6). Pre-restructuring equity value satisfies:

$$
\begin{aligned}
E_{l}\left(X, C_{l}\right)=(1-\tau) & {\left[F\left(X, C_{l}\right)-F\left(X_{l}, C_{l}\right) \mathcal{L}(X)+\left(\frac{R\left(X_{r}\right)}{1-\tau}-\frac{C^{*}\left(X_{r}\right)-C_{l}}{r}\right.\right.} \\
& \left.\left.-F\left(X_{d}, C^{*}\left(X_{r}\right)\right) \mathcal{D}\left(X_{r}\right)\right) \mathcal{H}(X)\right]
\end{aligned}
$$

for all $X \in\left(X_{l}, X_{r}\right)$, where $F(X, C)$ is as in Proposition 5, $X_{d}$ is defined in (14) with $C=C^{*}\left(X_{r}\right)$ in (12), and post-restructuring equity value $E\left(X, C^{*}\left(X_{r}\right)\right)$ is given by (8). Pre-restructuring firm value satisfies:

$$
\begin{aligned}
V_{l}\left(X, C_{l}\right)= & U(X)+\frac{\tau C_{l}}{r}[1-\mathcal{L}(X)-\mathcal{H}(X)]-\alpha U\left(X_{l}\right) \mathcal{L}(X) \\
& +\left[\frac{\tau C^{*}\left(X_{r}\right)}{r}\left[1-\mathcal{D}\left(X_{r}\right)\right]-\alpha U\left(X_{d}\right) \mathcal{D}\left(X_{r}\right)+R\left(X_{r}\right)\right] \mathcal{H}(X)
\end{aligned}
$$

for all $X \in\left(X_{l}, X_{r}\right)$, and post-restructuring firm value $V\left(X, C^{*}\left(X_{r}\right)\right)$ is given by (9). The stochastic discount factors $\mathcal{L}(X)$ and $\mathcal{H}(X)$ are as in Proposition 5 with $X_{h}=X_{r} . a$ and $z$ are as in (10) and (27).

Proposition 6 provides analytic expressions for the manager's default and restructuring policies. As shown in the Proposition, the growth and risk of earnings are again essential in determining financial structure when the basic model is extended to capture debt dynamics. For the baseline set of parameter values from Section III.A along with fixed costs of $\Gamma=\$ 25$ and variable costs of $\gamma=2.5 \%$, Figure 2 charts numerical results for debt dynamics and managerial traits that rely on the solutions above. The figure illustrates the following effects of growth and risk perception biases in the dynamic tradeoff model.

First, the option to adjust capital structure dynamically raises firm value and decrease debt levels, which is known from studies such as Goldstein, Ju, and Leland (2001). As depicted in Graphs A and B, the firm value-maximizing debt coupon is $C_{l}=\$ 3.41$ in the dynamic tradeoff model. This is substantially lower than the choice of $\$ 13.55$ in the basic model. Based on initial debt and firm values of $\$ 41.39$ and $\$ 293.01$, this dynamic policy implies leverage of $\ell_{l}=14.12 \%$ at time 0 and leverage of $\ell=55.65 \%$ at the restructuring date, consistent with the results on the basic model in Table 1. Second, growth and risk perception biases also lead to increased initial debt levels in the dynamic tradeoff model, which reinforces Proposition 3 for debt dynamics. Moreover, the dynamic extension predicts that at the time of the restructuring, biased managers select a debt level that exceeds the one selected by unbiased managers. Thus, managers with 
FIGURE 2

Debt Dynamics and Managerial Traits

Graphs A-B depict the effect of growth and risk perception biases on initial debt levels when the manager selects the debt and restructuring levels, while shareholders determine default levels. Graphs C-D chart the effect of growth and risk perception biases on restructuring levels when the manager chooses debt and restructuring levels, while shareholders determine default levels. The dashed lines indicate unbiased decisions, and the baseline parameter values of $X_{0}=\$ 20$ $r=8 \%, \mu=1 \%, \sigma=25 \%, \alpha=25 \%, \tau=15 \%, \Gamma=\$ 25$, and $\gamma=2.5 \%$ are assumed.
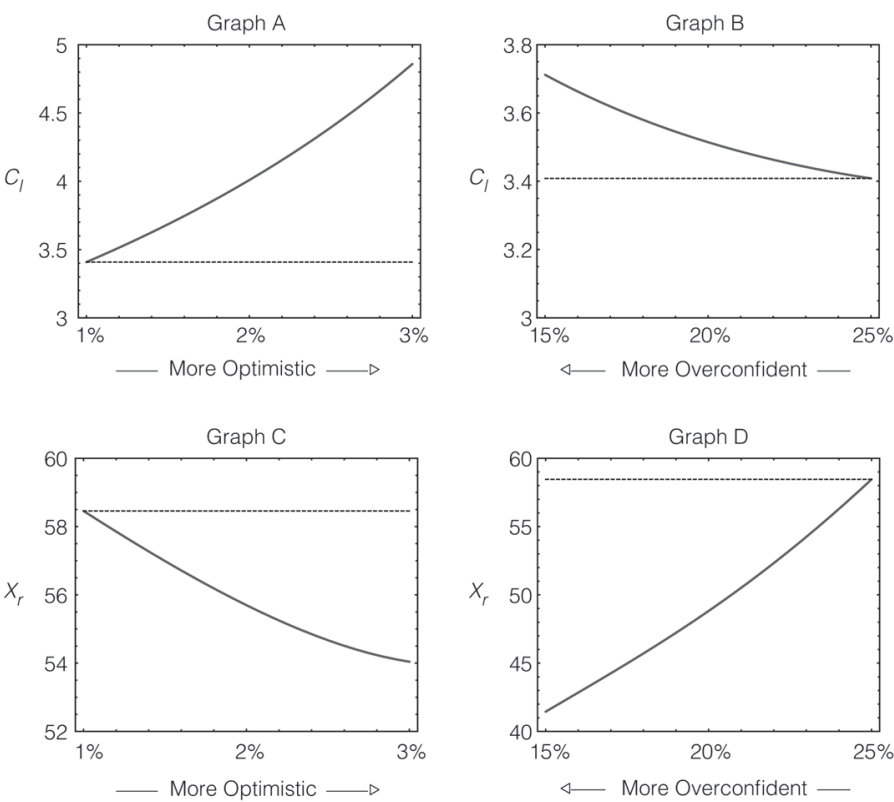

growth and risk perception biases choose higher initial and restructured leverage. Third, Graphs C and D illustrate that managers with growth and risk perception biases exercise debt restructuring options earlier. That is, unbiased managers enter the restructuring at the threshold $X_{r}=\$ 58.46$ in the baseline environment, while biased managers select restructuring thresholds that are strictly below this point.

Overall, observe that these findings broadly confirm the results in Section III and provide new insights on the dynamics of capital structure decisions. From an empirical standpoint, this means that in a cross-section of firms, one would expect that biased managers' firms, exhibit dynamically higher leverage ratios, more new debt issues, and shorter empirically observable refinancing periods.

\section{Conclusions}

A nascent literature in financial economics focuses on managers' personality traits. This article's objective is to develop a tradeoff model to study the financial policy implications of optimism and overconfidence, two well-documented biases in the psychology literature on judgment under uncertainty. In particular, I contend that extending traditional capital structure theory to account for these 
managerial traits can tighten some important gaps between known theoretical predictions and unresolved empirical facts.

The model shows that managers with growth and/or risk perception biases tend to choose higher debt levels and issue new debt more often compared to otherwise identical unbiased managers. As a result, managerial traits can cause significant variation in capital structures, although the underlying firm and industry characteristics are constant. Contrary to the conventional wisdom, biased managers need not follow a pecking order. While growth perception bias leads to a standard pecking order, risk perception bias implies a reverse pecking order, because a manager biased in this way regards equity as overvalued and, at the same time, views debt as undervalued by the market. Thus, tradeoff theory need not be inconsistent with existing empirical evidence favoring the pecking order hypothesis. The model also offers a possible explanation for why certain firms, e.g., Microsoft, issue mostly equity rather than a balanced mixture of debt and equity. I conclude that managerial traits theory complements and extends tradeoff theory in interesting ways, which suggests a rethinking of the way capital structure tests are conducted.

By extending the basic model to examine interactions between agency problems and managerial traits, I generate novel predictions regarding the effect of growth and risk perception biases on corporate financial policy and firm value. Due to the overissuance of debt and the perceived wedge between the cost of internal and external funds, managerial biases are in principle costly to shareholders. Perhaps surprisingly, however, I find that mildly biased managers can enhance firm value, as determined by rational investors, for two reasons. First, because higher debt levels restrain managers from diverting discretionary funds, mildly biased managers unknowingly mitigate manager-shareholder conflicts over payout policy, leading to better firm performance. Second, though higher debt levels generally delay irreversible investments, mildly biased managers' investment decisions can reduce this bondholder-shareholder conflict over investment policy, permitting better firm performance. In line with survey evidence in Puri and Robinson (2007), however, I find that extreme managerial biases are detrimental to the firm.

As mentioned earlier, the complex and infrequent decisions in this article are not conducive to learning. Extending the model to a gradual convergence of heterogeneous beliefs may be potentially interesting, but technically challenging. Incorporation of learning would probably attenuate the effect of managerial traits on corporate financial policy and firm value. In reality, however, the frequent turnover of managers and the managerial myopia that focuses on short-term results limit the extent to which managerial biases can be reduced by learning in the long run. Against this backdrop, the results in this article could therefore be regarded as an upper bound, while the true effect of managerial traits probably lies somewhere in between this case and the unbiased benchmark case.

Psychologists claim that there are also beneficial social effects of mild behavioral biases. Optimistic and overconfident people tend to be happier, more popular, more motivated, and more willing to help others. At the same time, though, biased managers should make realistic forecasts. This paper's recommendation for corporate practice is therefore that rational shareholders must draw a fine line 
between taking advantage of the potential growth and risk perception biases of their agents and instilling a good sense of realism in their agents' minds to avoid extreme cognitive errors. Finally, the overall costs and benefits of managerial traits are a function of other factors, too, such as firm and industry characteristics and, in particular, managerial ability. This suggests that further extension of managerial traits theory will prove fruitful.

\section{Appendix}

\section{Proof of Proposition 1}

Given (1), the asset value $A(X)$ of a claim paying dividends $m X_{t}+k$ satisfies the equilibrium condition:

$$
r A\left(X_{t}\right)=m X_{t}+k+\frac{1}{d t} \mathbb{E}_{t}^{\mathcal{Q}}\left[A\left(X_{t+d t}\right)\right] .
$$

The expression on the 1.h.s. of (A1) is the equilibrium return an investor requires under the measure $\mathcal{Q}$. The first two terms on the r.h.s. of (A1) are the flow benefits in period $t$, while the third term is the expected capital gain of $A(X)$ from period $t$ to $t+d t$. Applying Itô's Lemma to (A1) and suppressing time subscripts yields an ordinary differential equation:

$$
r A(X)=m X+k+0.5 \sigma^{2} X^{2} A_{X X}(X)+\mu X A_{X}(X),
$$

which has a general solution of the form:

$$
A(X)=B_{1} X^{a}+B_{2} X^{z}+m X /(r-\mu)+k / r
$$

where $a<0$ and $z>1$ denote the characteristic roots of the quadratic equation $r=$ $0.5 \sigma^{2}(x-1) x+\mu x$, and where suitable boundary conditions pin down the unknown constants $A_{1}$ and $A_{2}$. Setting $m=0, k=C$, and solving (A2) subject to the asymptotic and value-matching conditions:

$$
\begin{aligned}
\lim _{X \rightarrow \infty} D(X, C) & =C / r \quad \text { and } \\
D\left(X_{d}, C\right) & =(1-\alpha) U\left(X_{d}\right)
\end{aligned}
$$

yields the expression for debt value in (6) with (7) given by (A3) for $m=(1-\tau)$ and $k=0$. Setting $m=(1-\tau), k=(1-\tau) C$, and solving (A2) subject to the asymptotic and value-matching conditions:

$$
\begin{aligned}
\lim _{X \rightarrow \infty} E(X, C) & =(1-\tau) X /(r-\mu)-(1-\tau) C / r \text { and } \\
E\left(X_{d}, C\right) & =0
\end{aligned}
$$

yields the expression for equity value in (8). Finally, setting $m=(1-\tau), k=\tau C$, and solving (A2) subject to the asymptotic and value-matching conditions:

$$
\begin{aligned}
\lim _{X \rightarrow \infty} V(X, C) & =(1-\tau) X /(r-\mu)+\tau C / r \text { and } \\
V\left(X_{d}, C\right) & =0
\end{aligned}
$$


yields the expression for levered firm value in (9), which can be decomposed into unlevered firm value $U(X)$, plus tax shield value benefits of debt $T B(X, C)$, less bankruptcy costs of debt $B C(X, C)$ :

$$
V(X, C)=U(X)+\underbrace{\tau C / r[1-\mathcal{D}(X)]}_{T B(X, C)}-\underbrace{\alpha U\left(X_{d}\right) \mathcal{D}(X)}_{B C(X, C)} \quad \forall X \geq X_{d},
$$

where the derivations of tax benefits, $T B(X, C)$, and bankruptcy costs, $B C(X, C)$, are suppressed as they are similar to the previous derivations.

\section{Proofs of Propositions 2 and 3}

For the effect of growth and risk perception biases on default levels, let

$$
\begin{aligned}
X_{d}^{*}(X ; \mu, \sigma) & =X[g(X ; \mu, \sigma)]^{h(X ; \mu, \sigma)}, \\
g(X ; \mu, \sigma) & =1-\{a(\mu, \sigma)[\tau+\alpha(1-\tau)]\} / \tau>0, \quad \text { and } \\
h(X ; \mu, \sigma) & =1 / a(\mu, \sigma)<0 .
\end{aligned}
$$

Then differentiate (A11) w.r.t. $\mu$ and $\sigma^{2}$ using the chain rule:

$$
\frac{\partial X_{d}^{*}(\cdot)}{\partial \mu}=g(\cdot)^{h(\cdot)}\left[\frac{h(\cdot)}{g(\cdot)} \frac{\partial g(\cdot)}{\partial \mu}+\ln [g(\cdot)] \frac{\partial h(\cdot)}{\partial \mu}\right],
$$

and after redefining $h(X ; \mu, \sigma)=-1 / a(\mu, \sigma)$ by factoring out a minus sign:

$$
\frac{\partial X_{d}^{*}(\cdot)}{\partial\left(\sigma^{2}\right)}=-g(\cdot)^{h(\cdot)}\left[\frac{h(\cdot)}{g(\cdot)} \frac{\partial g(\cdot)}{\partial\left(\sigma^{2}\right)}+\ln [g(\cdot)] \frac{\partial h(\cdot)}{\partial\left(\sigma^{2}\right)}\right]
$$

where using the variance again simplifies the tedious algebra. First, in case of a growth perception bias:

$$
\begin{aligned}
& \frac{\partial g(\cdot)}{\partial \mu}=-\frac{\tau+\alpha(1-\tau)}{\sigma^{2} \tau}\left[1+\frac{\mu-\sigma^{2} / 2}{\sqrt{\left(\mu-\sigma^{2} / 2\right)^{2}+2 r \sigma^{2}}}\right]<0 \quad \text { and } \\
& \frac{\partial h(\cdot)}{\partial \mu}=\frac{\sigma^{2}}{\sqrt{\left(\mu-\sigma^{2} / 2\right)^{2}+2 r \sigma^{2}}} \frac{1}{\left(\mu-\sigma^{2} / 2\right)+\sqrt{\left(\mu-\sigma^{2} / 2\right)^{2}+2 r \sigma^{2}}}>0 .
\end{aligned}
$$

Second, in case of a risk perception bias:

$$
\begin{aligned}
\frac{\partial g(\cdot)}{\partial\left(\sigma^{2}\right)}= & \frac{\tau+\alpha(1-\tau)}{2 \sigma^{4} \tau \sqrt{\left(\mu-\sigma^{2} / 2\right)^{2}+2 r \sigma^{2}}} \\
& \times\left[(2 r-\mu) \sigma^{2}+2 \mu\left(\mu+\sqrt{\left(\mu-\sigma^{2} / 2\right)^{2}+2 r \sigma^{2}}\right)\right]>0 \quad \text { and } \\
\frac{\partial h(\cdot)}{\partial\left(\sigma^{2}\right)}= & \frac{1}{4 r}\left[\frac{(2 r-\mu)+\sigma^{2}}{\sqrt{\left(\mu-\sigma^{2} / 2\right)^{2}+2 r \sigma^{2}}}\right]>0 .
\end{aligned}
$$

Collecting and evaluating terms shows that $\partial X_{d}^{*}(\cdot) / \partial \mu>0$ and $\partial X_{d}^{*}(\cdot) / \partial \sigma<0$ for all $r>\mu$. Using similar arguments as above, it is possible to prove that the effect of growth and risk perception biases on debt levels is as described in Proposition 3. 


\section{Proof of Proposition 4}

The agency cost of diverting funds $A C(X, C)$ is of the form (A3) and solves (A2) when $(m X+k)$ is replaced by $0, \psi(X-C)$, and, $\psi J$ for the three different regions with $\psi=r-\delta$. Therefore, define:

$$
\begin{array}{ll}
A C_{1}(X, C)=B_{1} X^{a}+B_{2} X^{z} & \forall X \in[0, C[, \\
A C_{2}(X, C)=B_{3} X^{a}+B_{4} X^{z}+\psi[X /(r-\mu)-C / r] & \forall X \in[C, C+J[, \quad \text { and } \\
A C_{3}(X, C)=B_{5} X^{a}+B_{6} X^{z}+\psi J / r & \forall X \in[C+J, \infty[,
\end{array}
$$

where the constants are determined by boundary conditions. That is, there is an asymptotic condition:

$$
\lim _{X \rightarrow \infty} A C_{3}(X, C)=\psi J / r
$$

In addition, there are three value-matching conditions and two smooth-pasting conditions:

$$
\begin{gathered}
A C_{1}\left(X_{d}, C\right)=0 \\
\left.A C_{1}(X, C)\right|_{X=C}=\left.A C_{2}(X, C)\right|_{X=C}, \\
\left.A C_{2}(X, C)\right|_{X=C+J}=\left.A C_{3}(X, C)\right|_{X=C+J}, \\
\left.\left(\partial A C_{1}(X, C) \partial X\right)\right|_{X=C}=\left.\left(\partial A C_{2}(X, C) / \partial X\right)\right|_{X=C}, \quad \text { and } \\
\left.\left(\partial A C_{2}(X, C) / \partial X\right)\right|_{X=C+J}=\left.\left(\partial A C_{3}(X, C) \partial X\right)\right|_{X=C+J} .
\end{gathered}
$$

Simple algebraic derivations yield the analytic expressions reported in the proposition.

\section{Proof of Propositions 5 and 6}

The manager maximizes (perceived) firm value subject to the lower and upper boundaries; i.e., the threshold $X_{l}$ for default on the low coupon and the threshold $X_{r}$ for debt restructuring, given that the restructured debt level $C^{*}\left(X_{r}\right)$ and the threshold $X_{d}$ for default on the restructured debt level are known. This involves solving the following optimization problem subject to two smooth-pasting conditions.

$$
C_{l}^{*}(X) \in \arg \max _{C_{l}} V_{l}\left(X, C_{l}\right),
$$

subject to

$$
\begin{aligned}
& \partial E_{l}\left(X, C_{l}\right) / \partial X_{l}=0 \text { and } \\
& \partial E_{l}\left(X, C_{l}\right) / \partial X_{r}=\partial E\left(X, C^{*}\left(X_{r}\right)\right) / \partial X_{r} .
\end{aligned}
$$

Using the equity values in Propositions 1 and 6 to evaluate (A23) and (A24) yields, after simple algebra, the analytic expressions in (36) and (37). Using similar smooth-pasting arguments as above, it is possible to derive the analytic expressions for $X_{l}$ and $X_{h}$ in (30) to (32) of Proposition 5.

Debt value in (6) follows from setting $m=0, k=C$, and solving (A2) s.t. valuematching conditions:

$$
\begin{aligned}
& D_{l}\left(X_{r}, C_{l}\right)=P \text { and } \\
& D_{l}\left(X_{l}, C_{l}\right)=(1-\alpha) U\left(X_{l}\right) .
\end{aligned}
$$


Equity value in (6) follows from setting $m=(1-\tau), k=(1-\tau) C$, and the value-matching conditions:

$$
\begin{aligned}
& E_{l}\left(X_{r}, C_{l}\right)=E\left(X_{r}, C^{*}\left(X_{r}\right)\right)+R\left(X_{r}\right) \text { and } \\
& E_{l}\left(X_{l}, C_{l}\right)=0 .
\end{aligned}
$$

Firm value in (6) follows from setting $m=(1-\tau), k=\tau C$, and the value-matching conditions:

$$
\begin{aligned}
& V_{l}\left(X_{r}, C_{l}\right)=V\left(X_{r}, C^{*}\left(X_{r}\right)\right)+R\left(X_{r}\right) \text { and } \\
& V_{l}\left(X_{l}, C_{l}\right)=(1-\alpha) U\left(X_{l}\right) .
\end{aligned}
$$

Again, using similar value-matching arguments as above, it is possible to derive the expressions for debt, equity, and firm values reported in Proposition 5.

\section{References}

Ben-David, I.; J. Graham; and C. Harvey. "Managerial Overconfidence and Corporate Policies.” Working Paper, Duke University (2006).

Berger, P.; E. Ofek; and D. Yermack. "Managerial Entrenchment and Capital Structure Decisions." Journal of Finance, 52 (1997), 1411-1438.

Bernardo, A., and I. Welch. "On the Evolution of Overconfidence and Entrepreneurs." Journal of Economics and Management Strategy, 10 (2001), 301-330.

Bertrand, M., and A. Schoar. "Managing with Style: The Effect of Managers on Firm Policies." Quarterly Journal of Economics, 118 (2003), 301-330.

Childs, P.; D. Mauer; and S. Ott. "Interactions of Corporate Financing and Investment Decisions: The Effects of Agency Conflicts." Journal of Financial Economics, 76 (2005), 667-690.

De Meza, D., and C. Southey. "The Borrower's Curse: Optimism, Finance and Entrepreneurship." Economic Journal, 106 (1996), 375-386.

Dittmar, A., and J. Mahrt-Smith. "Corporate Governance and the Value of Cash Holdings." Journal of Financial Economics, 83 (2007), 599-634.

Einhorn, H. "Overconfidence in Judgment." New Directions for Methodology of Social and Behavioral Science, 4 (1980), 1-16.

Fischer, E.; R. Heinkel; and J. Zechner. "Dynamic Capital Structure Choice: Theory and Tests." Journal of Finance, 44 (1989), 19-40.

Frank, M., and V. Goyal. "Testing the Pecking Order Theory of Capital Structure." Journal of Financial Economics, 67 (2003), 217-248.

Gervais, S.; J. Heaton; and T. Odean. "Overconfidence, Investment Policy, and Manager Welfare." Working Paper, Duke University (2006).

Goel, A., and A. Thakor. "Overconfidence, CEO Selection, and Corporate Governance." Working Paper, Washington University in St. Louis (2005).

Goldstein, R.; N. Ju; and H. Leland. "An EBIT-Based Model of Dynamic Capital Structure.” Journal of Business, 74 (2001), 483-512.

Graham, J., and C. Harvey. "The Theory and Practice of Corporate Finance: Evidence from the Field." Journal of Financial Economics, 60 (2001), 187-243.

Grifin, D., and A. Tversky. "The Weighing of Evidence and the Determinants of Confidence." Cognitive Psychology, 24 (1992), 411-435.

Grossman, S., and O. Hart. "Financial Structure and Managerial Incentives." In The Economics of Information and Uncertainty, J. McCall, ed. Chicago: University of Chicago Press (1982).

Harris, M., and A. Raviv. "Differences of Opinion Make a Horse Race." Review of Financial Studies, 6 (1993), 473-506.

Harrison, J., and D. Kreps. "Speculative Investor Behavior in a Stock Market with Heterogeneous Expectations." Quarterly Journal of Economics, 92 (1978), 323-336.

Hart, O., and J. Moore. "Default and Renegotiation: A Dynamic Model of Debt." Quarterly Journal of Economics, 113 (1998), 1-41.

Heaton, J. "Managerial Optimism and Corporate Finance." Financial Management, 31 (2002), 33-45.

Jensen, M. "Agency Costs of Free Cash Flow, Corporate Finance, and Takeovers." American Economic Review, 76 (1986), 323-329. 
Jensen, M., and W. Meckling. "The Theory of the Firm: Managerial Behavior, Agency Costs, and Ownership Structure.” Journal of Financial Economics, 3 (1976), 305-360.

Ju, N.; R. Parrino; A. Poteshman; and M. Weisbach. "Horses and Rabbits? Optimal Dynamic Capital Structure from Shareholder and Manager Perspectives." Journal of Financial and Quantitative Analysis, 40 (2005), 259-281.

Kahneman, D.; P. Slovic; and A. Tversky. Judgment under Uncertainty: Heuristics and Biases. Cambridge and New York: Cambridge University Press (1982).

Kahnemann, D., and D. Lovallo. "Timid Choices and Bold Forecasts: A Cognitive Perspective on Risk Taking." Management Science, 39 (1993), 17-31.

Kyle, A., and F. Wang. "Speculation Duopoly with Agreement to Disagree: Can Overconfidence Survive the Market Test?" Journal of Finance, 52 (1997), 2073-2090.

Lambrecht, B., and S. Myers. "Debt and Managerial Rents in a Real-Options Model of the Firm." Working Paper, University of Lancaster (2006).

Leland, H. "Corporate Debt Value, Bond Covenants and Optimal Capital Structure." Journal of Finance, 49 (1994), 1213-1252.

Malmendier, U.; G. Tate; and J. Yan. "Corporate Financial Policies with Overconfident Managers," Working Paper, UC Berkeley (2006).

Mauer, D., and S. Ott. "Agency Costs, Underinvestment, and Optimal Capital Structure: The Effect of Growth Options to Expand." In Project Flexibility, Agency, and Competition, M. Brennan and L. Trigeorgis, eds. Oxford and New York: Oxford University Press (2000).

Mauer, D., and S. Sarkar. "Real Options, Agency Conflicts, and Optimal Capital Structure." Journal of Banking and Finance, 29 (2005), 1405-1428.

Mauer, D., and A. Triantis. "Interactions of Corporate Financing and Investment Decisions: A Dynamic Framework." Journal of Finance, 49 (1994), 1253-1277.

Mello, A., and J. Parsons. "Measuring the Agency Cost of Debt." Journal of Finance, 47 (1992), $1887-1904$.

Modigliani, F., and M. Miller. "The Cost of Capital, Corporation Finance, and the Theory of Investment." American Economic Review, 48 (1958), 261-297.

Morellec, E. "Can Managerial Discretion Explain Observed Leverage Ratios?" Review of Financial Studies, 17 (2004), 257-294.

Myers, S. "Determinants of Corporate Borrowing." Journal of Financial Economics, 5 (1977), $147-175$.

Myers, S., and N. Majluf. "Corporate Financing and Investment Decisions when Firms Have Information that Investors Do Not Have.” Journal of Financial Economics, 13 (1984), 187-221.

Odean, T. "Volume, Volatility, Price, and Profit when All Traders Are Above Average, Journal of Finance 53 (1998), 1887-1934.

Parrino, R., and M. Weisbach. "Measuring Investment Distortions Arising from StockholderBondholder Conflicts." Journal of Financial Economics, 53 (1999), 3-42.

Puri, M., and D. Robinson. "Optimism and Economic Choice." Journal of Financial Economics, 86 (2007), 71-99.

Roll, R. "The Hubris Hypothesis of Corporate Takeovers." Journal of Business, 59 (1986), 197-216.

Williams, J. "Capital Asset Prices with Heterogeneous Beliefs." Journal of Financial Economics, 5 (1977), 219-239. 